\title{
Thyroid hormone affects both endothelial and vascular smooth muscle cells in rat arteries
}

Yin $\mathrm{Cai}^{1}{ }^{1}$, Michael M. Manio ${ }^{1}$, George P.H. Leung ${ }^{1}$, Aimin $\mathrm{Xu}^{1,2}$, Eva H.C. Tang ${ }^{1,3,{ }^{*}}$ and Paul M. Vanhoutte ${ }^{1}$

1 Department of Pharmacology and Pharmacy and State Key Laboratory of Pharmaceutical Biotechnology, Li Ka Shing Faculty of Medicine, The University of Hong Kong, Hong Kong, China

${ }^{2}$ Department of Medicine, Li Ka Shing Faculty of Medicine, The University of Hong Kong, Hong Kong, China

${ }^{3}$ Department of Physiology, Li Ka Shing Faculty of Medicine, The University of Hong Kong, Hong Kong, China

${ }^{*}$ Corresponding author: Dr. Eva H.C. Tang

Department of Pharmacology and Pharmacy, Li Ka Shing Faculty of Medicine

The University of Hong Kong

L2-26C, 2/F, Laboratory Block, 21 Sassoon Road, Hong Kong SAR, China

Tel: (852)3917-9027; Fax: (852)2817-0859

Email: evatang1@hku.hk 


\section{Abstract}

Hypothyroidism impairs endothelium-dependent dilatations, while hyperthyroidism augments the production of endothelial nitric oxide. Thus, experiments were designed to determine if thyroid hormone causes endothelium-dependent responses, or alleviates diabetic endothelial dysfunction. Isometric tension was measured in rings with or without endothelium of arteries from normal and diabetic Sprague-Dawley rats. Release of 6-keto prostaglandin $F_{1 \alpha}$ and thromboxane $B_{2}$ were measured by enzyme linked immunosorbent assay and protein levels [endothelial nitric oxide synthase (eNOS), cyclooxygenases (COX)] by immunoblotting. Triiodothyronine $\left(T_{3}\right)$ caused concentration-dependent $\left(3 \times 10^{-6}\right.$ to $\left.3 \times 10^{-5} \mathrm{M}\right)$ relaxations in mesenteric $\left(\mathrm{pEC}_{50}, 4.96 \pm 0.19\right)$ and femoral ( $\left.\mathrm{pEC} 50,4.57 \pm 0.35\right)$ arteries without endothelium. In femoral arteries of rats with diabetes, 5-methylamino-2-(2S,3R,5R,8S,9S)-3,5,9-trimethyl-2-(1-oxo-(1H-pyrrol-2-

-yl)propan-2-yl)-1,7-dioxaspiro-(5,5)undecan-8-yl)methyl)benzooxazole-4-carboxylic acid (A23187, $3 \times 10^{-7}$ to $10^{-6} \mathrm{M}$ ) caused partly endothelium-dependent contractions. After chronic $\mathrm{T}_{3}$-treatment with $(10 \mu \mathrm{g} / \mathrm{kg} /$ day; four weeks), the contractions to $\mathrm{A} 23187$ of preparations with and without endothelium were comparable, the thromboxane $B_{2}$-release was reduced (by $\left.38.1 \pm 9.2 \%\right)$. The $\mathrm{pEC}_{50}$ of 9, 11-dideoxy-11 $\alpha, 9 \alpha$-epoxymethanoprostaglandin $\mathrm{F}_{2 \alpha}$ (U46619, TP-receptor agonist) was increased in $T_{3}$-treated diabetic rats compared with controls ( $8.53 \pm 0.06$ vs $7.94 \pm 0.09$ ). The protein expression of eNOS increased (by 228\%) but that of COX-1 decreased (by 35\%) after chronic $T_{3}$ treatment. In human umbilical vein endothelial cells incubated for one week with $T_{3}$ $\left(10^{-10}\right.$ to $\left.10^{-7} \mathrm{M}\right)$ in the presence but not in the absence of interleukin- $1 \beta(1 \mathrm{ng} / \mathrm{ml})$, the expression of eNOS was increased compared to control. In conclusion, thyroid hormone acutely relaxes 
mesenteric and femoral vascular smooth muscle, but given chronically reduces the release of endothelium-derived vasoconstrictor prostanoids while enhancing the responsiveness of TP receptors of vascular smooth muscle.

\section{Key words}

COX-1; endothelium-derived contracting factor(s); eNOS; type 1 diabetes; TP receptors

\section{Chemical compounds studied in this article}

3,5,3'-tri-iodothyronine (PubChem CID: 5920); A23187 (PubChem CID: 40486); acetylcholine (PubChem CID: 6060); indomethacin (PubChem CID: 3715); L-NAME (PubChem CID: 39386); phenylephrine (PubChem CID: 6041); U46619 (PubChem CID: 5311493)

\section{Abbreviations}

A23187,

5-methylamino-2-(2S,3R,5R,8S,9S)-3,5,9-trimethyl-2-(1-oxo-(1H-pyrrol-2-yl)propan-2-yl)-1,7-dioxa spiro-(5,5)undecan-8-yl)methyl)benzooxazole-4-carboxylic acid; COX, cyclooxygenase; EC, endothelial cell; EDCFs, endothelium-derived contracting factors; eNOS, endothelial nitric oxide synthase; HUVECs, human umbilical vein endothelial cells; L-NAME, Nw-nitro-L-arginine methyl $\begin{array}{llll}\text { ester; No, nitric } & \text { oxide; }\end{array}$ 3-[(6-amino-(4-chlorobenzensulphonyl)-2-methyl-5,6,7,8-tetrahydronapht]-1-yl)propionic acid; SD, Sprague-Dawley; SHR, spontaneously hypertensive rat; $T_{3}, 3,5$, 3'-tri-iodothyronine; TP receptor, thromboxane prostanoid receptor; U46619, 9, 11-dideoxy-11 $\alpha$, $9 \alpha$-epoxymethanoprostaglandin $F_{2 \alpha}$ 


\section{Introduction}

The endothelium, a thin layer of cells lining the interior surface of blood vessels, can control local vascular tone. It does so by releasing endothelium-derived relaxing factors (Furchgott and Vanhoutte, 1989; Furchgott and Zawadzki, 1980), including nitric oxide (NO) and/or several other endothelium-derived hyperpolarizing substances (Félétou and Vanhoutte, 2007, 2006; Vanhoutte 2004). In addition, in particular in arteries of obese, diabetic or hypertensive animals, the release of endothelium-derived contracting factors [EDCFs], causing activation of the underlying smooth muscle cells (Tang and Vanhoutte, 2010; Vanhoutte, 2011; Wong and Vanhoutte, 2010c), contributes to endothelium-dependent changes in vascular diameter.

Several hormones can trigger endothelium-dependent responses. These include catecholamines acting on endothelial $\alpha 2$-adrenergic receptors (Vanhoutte and Miller, 1989), vasopressin and oxytocin activating V1-vasopressinergic receptors (Katusic et al., 1986, 1984), and insulin (Liu et al., 2012). Hormones, in particular estrogens, also chronically modulate endothelium-dependent responses (Chambliss and Shaul, 2002; Gisclard et al., 1988).

Hypothyroidism causes impaired endothelium-dependent dilatations (Taddei et al., 2003). Furthermore, diabetic patients have a higher prevalence of thyroid disorders compared to the normal population (Hage et al., 2011). Thyroid hormone is synthesized and stored in the follicular and the colloid cells of the thyroid gland and plays a role in differentiation, growth, and metabolism (Yen, 2001). The hormone also affects the cardiovascular system. Thus, hyperthyroidism results in increased heart rate and atrial fibrillation, while hypothyroidism causes 
opposite changes (Ichiki, 2010). Although thyroid hormone can cause vasodilatation (Carrillo-Sepúlveda et al., 2010; Ishikawa et al., 1989), its acute effect on endothelial cells is controversial, since both an absence of effect of 3,5, 3'-tri-iodothyronine $\left(T_{3}\right)$ on NO production (Ojamaa et al., 1996) and activation of endothelial NO synthase through the PI3K/Akt pathway (Hiroi et al., 2006) have been reported. Therefore, the present experiments were designed to determine in isolated arteries of normal rats whether or not the acute exposure to thyroid hormone causes or affects endothelium-dependent responses. Furthermore, clinical studies suggest impaired endothelium-dependent dilatations in hypothyroid patients (Lekakis et al., 1997) while hyperthyroidism causes excessive endothelial NO production (Napoli et al., 2001). Such an increased production of NO should reduce the occurrence of endothelium-dependent contractions (Tang et al., 2005a). Thus, the present study also investigated whether or not chronic treatment with thyroid hormone can alleviate the exaggerated EDCF-mediated responses that characterize the endothelial dysfunction resulting from type 1 diabetes (Shi et al., 2007a).

\section{Materials and Methods}

All experimental protocols were approved by The University of Hong Kong Committee on the Use of Live Animals for Teaching and Research.

\subsection{Experimental animals}

The experiments were performed on isolated arteries of male Sprague Dawley (SD) rats. The rats used to test the direct effect of thyroid hormone were eight weeks old (250-350g). To test the effect of the hormone on endothelial dysfunction, twelve weeks old rats $(450-600 \mathrm{~g})$ were made 
diabetic by the intraperitoneal administration of streptozotocin $[30 \mathrm{mg} / \mathrm{kg}$; dissolved in citric acid-trisodium citrate (0.2mM) buffer $(\mathrm{pH} 4.0-4.5)$ ] given once per day for three consecutive days (Shi et al., 2006). Seventy-two $h$ after the last injection, tail blood samples were obtained, and the glucose concentration was measured using a one-touch glucometer (LifeScan Inc., Milpitas, CA, USA). Induction of diabetes was considered successful when the fasting glucose level was higher than $16.6 \mathrm{mM}$. The diabetic rats were divided randomly into two groups, one receiving vehicle alone and the other a daily intraperitoneal injection of $T_{3}(10 \mu \mathrm{g} / \mathrm{kg} / \mathrm{day}) . T_{3}$ was selected over thyroxine, because it mediates the effects of the latter in vivo and is more widely used in experimental animals (Carrillo-Sepúlveda et al., 2010; Dillmann, 1982; Hiroi et al., 2006; Szkudelski et al., 2003). Doses of $3 \mu \mathrm{g} / \mathrm{kg}$ (considered physiological) and 30 or $50 \mu \mathrm{g} / \mathrm{kg}$ (considered pharmacological) of $T_{3}$ have been administrated daily to diabetic rats by others investigators (Dillmann, 1982; Szkudelski et al., 2003). Since $3 \mu \mathrm{g} / \mathrm{kg}$ has no obvious metabolic effect, preliminary experiments were performed using $10 \mu \mathrm{g} / \mathrm{kg}, 50 \mu \mathrm{g} / \mathrm{kg}$ and $100 \mu \mathrm{g} / \mathrm{kg}$ of $\mathrm{T}_{3}$, however, the latter two doses were severely toxic in diabetic rats, prompting the use of $10 \mu \mathrm{g} / \mathrm{kg} /$ day for further studies.

The rats were housed in the laboratory animal unit of The University of Hong Kong, and fed with normal chow. Water was provided ad libitum. The diabetic rats were studied four weeks after the last streptozotocin injection. On the day of the experiment, the non-fasting glucose level was measured again. After three $\mathrm{h}$ fasting, the rats were anesthetized with sodium pentobarbitone $(70 \mathrm{mg} / \mathrm{kg}$, intraperitoneally) and euthanized. Blood samples were collected from the inferior vena cava for measuring the $T_{3}$ level in serum. 


\subsection{Tissue preparation}

The thoracic aorta, mesenteric arteries or femoral arteries were dissected free and placed in ice-cold modified Krebs-Ringer solution of the following composition (mM): $\mathrm{NaCl} 120, \mathrm{KCL} 4.76$, $\mathrm{CaCl}_{2}$ 2.5, $\mathrm{MgSO}_{4}$ 1.18, $\mathrm{NaHCO}_{3}$ 25.0, $\mathrm{NaH}_{2} \mathrm{PO}_{4} 1.18$ and calcium disodium ethylenediaminetetraacetic acid 0.026 , glucose 5.5 (control solution). The blood vessels were cut into rings (3-4mm length in aorta, $1.5-2 \mathrm{~mm}$ length in mesenteric and femoral arteries). In some preparations, the endothelial cell layer was removed by the injection of $1 \mathrm{ml}$ of Triton $(0.5 \%$, diluted in control solution) in the artery prior to cutting it into rings.

\subsection{Isometric tension measurement}

The preparations were suspended in organ chambers, which contained warmed $\left(37^{\circ} \mathrm{C}\right)$, aerated $\left(95 \% \mathrm{O}_{2}, 5 \% \mathrm{CO}_{2}\right)$ control solution $(5 \mathrm{ml})$. They were connected to a force transducer and a bio-signal acquisition system (PowerLab, ADInstruments, Sydney, Australia) to record isometric tension. The rings were stretched to an optimal tension (2.5g in aorta, $2 \mathrm{~g}$ in mesenteric and $1 \mathrm{~g}$ in femoral arteries; determined in preliminary experiments; data not shown) and allowed to equilibrate for $90 \mathrm{~min}$. They were then exposed twice to $60 \mathrm{mM} \mathrm{KCL}$ to obtain a reference contraction.

To study the acute vascular effects of $\mathrm{T}_{3}$ in normal aorta, mesenteric or femoral arteries, U46619 $\left(3 \times 10^{-8} \mathrm{M}\right)$ was added to the chamber and when a stable contraction level had been reached, cumulative concentrations $\left(10^{-7}\right.$ to $\left.3 \times 10^{-5} \mathrm{M}\right)$ of $\mathrm{T}_{3}$ were administered. In some experiments, the rings were first incubated with pharmacological inhibitors (Table 1). The concentrations of the inhibitors tested were selected from earlier work in the laboratory or from the literature (Table 


\section{1).}

To examine whether or not the hormone has indirect effects, $10^{-7} \mathrm{M} \mathrm{T} 3$ (a concentration that has no direct effect) was added to the organ chamber; after an incubation period of $30 \mathrm{~min}$, cumulative concentrations of phenylephrine $\left(10^{-9}\right.$ to $\left.10^{-5} \mathrm{M}\right)$ were given to quiescent rings or cumulative concentrations of acetylcholine $\left(10^{-9}\right.$ to $\left.10^{-6} \mathrm{M}\right)$ were added during contractions to phenylephrine $\left(10^{-6} \mathrm{M}\right)$.

To study the effect of chronic treatment with thyroid hormone on endothelium-dependent relaxations, cumulative concentrations of acetylcholine $\left(10^{-9}\right.$ to $\left.10^{-6} \mathrm{M}\right)$ were added during contractions to phenylephrine $\left(10^{-6} \mathrm{M}\right)$ to rings of the aorta and mesenteric arteries from both $\mathrm{T}_{3}$ and vehicle treated diabetic rats.

To study the acute effect of thyroid hormone on endothelium-dependent contractions, rings of femoral arteries from diabetic rats were incubated with L-NAME $\left(3 \times 10^{-4} \mathrm{M}, 30 \mathrm{~min}\right)$ plus $\mathrm{T}_{3}$ $\left(10^{-7} \mathrm{M}\right)$, and exposed to cumulative concentrations of the calcium ionophore $A 23187\left(10^{-8}\right.$ to $\left.10^{-6} \mathrm{M}\right)$.

To study the effect of chronic treatment with thyroid hormone on endothelium-dependent contractions, rings of femoral arteries from both $T_{3}$ and vehicle treated group were incubated with L-NAME $\left(3 \times 10^{-4} \mathrm{M}, 30 \mathrm{~min}\right)$ or L-NAME $\left(3 \times 10^{-4} \mathrm{M}, 30 \mathrm{~min}\right)$ plus indomethacin [cyclooxygenase (COX) inhibitor, $5 \times 10^{-6} \mathrm{M}, 30 \mathrm{~min}$ ) or $\mathrm{S} 18886$ [thromboxane prostanoid (TP) receptor antagonist, $\left.10^{-7} \mathrm{M}, 30 \mathrm{~min}\right]$, and exposed to cumulative concentrations of the calcium ionophore A23187 $\left(10^{-8}\right.$ to $\left.10^{-6} \mathrm{M}\right)$. The responses to cumulative concentrations of phenylephrine or U46619 of femoral arteries without endothelium of $\mathrm{T}_{3}$ and vehicle treated rats were also determined. 


\subsection{Serum levels of thyroid hormone}

The serum $T_{3}$ levels from vehicle and $T_{3}$ treated diabetic rats were measured with an enzyme linked immunosorbent assay using commercially available kits [NO. 1700 for total $T_{3}$; Alpha Diagnostic International (San Antonio, TX, USA)]. The levels of $T_{3}$ are expressed as nanograms per deciliter of serum.

\subsection{Release of 6-keto prostaglandin $F_{1 \alpha}$ and thromboxane $B_{2}$}

Rings of femoral artery from both $T_{3}$ and vehicle treated diabetic rats were suspended in organ chambers containing warm and aerated control solution. After $90 \mathrm{~min}$ of equilibration and $30 \mathrm{~min}$ of incubation with L-NAME $\left(3 \times 10^{-4} \mathrm{M}\right)$, a single dose $\left(10^{-6} \mathrm{M}\right)$ of A23187 was added. After ten min, $0.5 \mathrm{ml}$ of the bath solution was sampled for the measurement of the release of 6-keto prostaglandin $F_{1 \alpha}$ and thromboxane $B_{2}$ using enzyme linked immunosorbent assay kits [Cayman Chemical Company (Ann Arbor, MI, USA)]. These samples were assayed in triplicates. The release of prostanoids is expressed in picograms per millimeter length of the ring (Wong et al., 2008; Wong et al., 2010b).

\subsection{Cell culture}

Human umbilical vein endothelial cells (HUVECs) were purchased from American Type Culture Collection (ATCC, Manassas, VA, USA), and cultured in Ham's Kaighn's Modification F12K medium (Invitrogen, Carlsbad, CA, USA) supplemented with $10 \%$ fetal bovine serum (Invitrogen), containing $1 \%$ penicillin/streptomycin $(100 \mathrm{U} / \mathrm{ml})$. Heparin $(0.1 \mathrm{mg} / \mathrm{ml})$ and endothelial cell growth factor $(0.05 \mathrm{mg} / \mathrm{ml})$ were added in the medium. The cells were incubated at $37^{\circ} \mathrm{C}$ in an 
atmosphere containing $5 \% \mathrm{CO}_{2}$ and $95 \%$ room air. To study the acute or chronic effect of thyroid hormone on the expression of endothelial nitric oxide synthase (eNOS), COX-1 and COX-2 in HUVECs, different concentrations $\left(10^{-10}\right.$ to $\left.10^{-7} \mathrm{M}\right)$ of $\mathrm{T}_{3}$ were administered for $30 \mathrm{~min}, 24 \mathrm{~h}$ or seven days. In some experiments, cells were also exposed to interleukin (IL)-1ß (1ng/ml).

\subsection{Protein extraction and Western blotting}

Femoral arteries (cut into small pieces) or cultured cells were homogenized in lysis buffer with the usual inhibitors (Li et al., 2011). The proteins were separated by sodium dodecyl sulfate-polyacrylamide gel electrophoresis, transferred to nitrocellulose membrane and detected with the appropriate antibodies (1:1000 eNOS monoclonal, 1:300 COX-1 monoclonal, 1:300 COX-2 polyclonal, 1:200 TP receptor polyclonal, 1:3000 $\beta$-actin monoclonal). Then, the blots were treated with horseradish peroxidase-conjugated anti-mouse or anti-rabbit antibody (1:3000), incubated with Amersham ${ }^{\mathrm{TM}} \mathrm{ECL}^{\mathrm{TM}}$ Western Blotting Detection Reagent (GE Healthcare, Boston, MA, USA) and subsequently exposed to X-ray film (Fuji Super RX medical X-ray film; Fuji Photo Film, Dusseldorf, Germany). ImageJ software (National Institutes of Health, MD, USA) was used to analyze the optical densities of the immunoreactive bands. The presence of protein was normalized to that of $\beta$-actin.

\subsection{Chemicals}

3,5,3'-tri-iodothyronine,

[5-methylamino-2-(2S,3R,5R,8S,9S)-3,5,9-trimethyl-2-(1-oxo-(1H-pyrrol-2-yl)propan-2-yl)-1,7-diox aspiro-(5,5)undecan-8-yl)methyl)benzooxazole-4-carboxylic acid], acetylcholine, $\mathrm{BaCl}_{2}$, 
charybdotoxin, glibenclamide, iberiotoxin, L-NAME [N $\omega$-nitro-L-arginine methyl ester], nifedipine, ODQ $\quad[1 \mathrm{H}-[1,2,4]$ oxadiazolo[4,3- $\alpha]$ quinoxalin-1-one $]$, ouabain, phenylephrine, indomethacin and thapsigargin were purchased from Sigma Chemical (St. Louis, MO, USA). U46619 [9, 11-dideoxy-11 $\alpha, 9 \alpha$-epoxymethanoprostaglandin $\left.F_{2 \alpha}\right]$ was purchased from Biomol (Plymouth Meeting, PA, USA). 1400W [N-(3-(Aminomethyl)benzyl)acetamidine] was purchased from Enzo Life science (Farmingdale, NY, USA). Rp-8-Br-cAMPs [8-bromoadenosine-3',5'-cyclic monophosphorothioate, Rp-isomer] was purchased from Biolog Life Science (Bremen, Germany). Calhex 231 [4-Chloro-N-[(1S,2S)-2-[[(1R)-1-(1-naphthalenyl)ethyl]amino]cyclohexyl]-benzamide hydrochloride] was purchased from Santa Cruz Biotechnology (Dallas, TX, USA). $\left[D-T r p^{7,9,10}\right]$-Substance $P$ was purchased from Tocris Bioscience (Bristol, UK). The eNOS monoclonal antibody was purchased from BD Transduction Laboratories (San Jose, CA, USA). KT5823 [2,3,9,10,11,12-hexahydro-10R-methoxy-2,9-dimethyl-1-oxo-9S,12R-epoxy-1H-diindolo[1, 2,3-fg:3',2',1'-kl]pyrrolo[3,4-i][1,6]benzodiazocine-10-carboxylic acid, methyl ester], coX-1 monoclonal, COX-2 polyclonal, TP receptor polyclonal antibodies and anti- $\beta$-actin were purchased from Cayman Chemical. S18886, 3-[(6-amino-(4-chlorobenzensulphonyl)-2-methyl-5,6,7,8-tetrahydronapht]-1-yl)propionic acid was a kind gift of the Institut de Recherches Servier (Suresnes, France). $T_{3}$ was dissolved in $50 \mathrm{mM}$ $\mathrm{NaOH}$ per $1 \mathrm{mg}$, U46619 was prepared in absolute ethanol. A23187 and ODQ were dissolved in absolute DMSO (0.1\% in the organ chamber). All other chemicals were prepared in deionized water. Concentrations are expressed as final molar concentrations.

\subsection{Data analysis}


Relaxations are expressed as percentage of the contractions to either phenylephrine or U46619, and contractions are expressed as a percentage of the reference response to $60 \mathrm{mM} \mathrm{KCL}$ obtained at the beginning of the experiment. The $\mathrm{pEC} \mathrm{C}_{50}$ is defined as the negative logarithm to base 10 of the $\mathrm{EC}_{50}$, which is the concentration of an agonist required to produce $50 \%$ of the maximal possible effect. Data are presented as means \pm S.E.M.; $\mathrm{n}$ refers to the number of rats or cell cultures. Statistical analysis was done by one or two-way analysis of variance. The results were analyzed with and graphed by Prism version 5 (GraphPad Software Inc. San Diego, CA). Differences were considered to be statistically significant when P was less than 0.05 .

\section{Results}

\subsection{Normal SD rats}

\subsubsection{Vascular responsiveness}

\subsubsection{Direct effects}

Cumulative concentrations $\left(10^{-7}\right.$ to $\left.3 \times 10^{-5} \mathrm{M}\right)$ of $\mathrm{T}_{3}$ did not cause significant changes in tension in aortic rings with or without endothelium of normal rats. In mesenteric arteries, $T_{3}$, from $3 \times 10^{-7}$ to $3 \times 10^{-5} \mathrm{M}$, caused significant and comparable decreases in tension in preparations with and without endothelium contracted with U46619 $\left(3 \times 10^{-8} \mathrm{M}\right)$. Similar results were obtained in femoral arteries (Fig. 1). The $\mathrm{T}_{3}$-induced relaxations in U46619 pre-contracted mesenteric arteries without endothelium were not affected significantly by inhibitors of NOS [L-NAME $\left(3 \times 10^{-4} \mathrm{M}\right)$ and $1400 \mathrm{~W}$ $\left(10^{-5} \mathrm{M}\right)$ ], of potassium channels [iberiotoxin $\left(10^{-7} \mathrm{M}\right)$, charybdotoxin $\left(10^{-7} \mathrm{M}\right), \mathrm{BaCl}_{2}\left(10^{-6} \mathrm{M}\right)$ or glibenclamide $\left(10^{-5} \mathrm{M}\right)$ ], of $\mathrm{Na}^{+}-\mathrm{K}^{+}$-ATPase [ouabain $\left(5 \times 10^{-7} \mathrm{M}\right)$ ], of L-type calcium channels 
[nifedipine $\left(10^{-7} \mathrm{M}\right)$ ], of the calcium sensing receptor [calhex $231\left(3 \times 10^{-6} \mathrm{M}\right)$ ], of G-proteins [pertussis toxin $(400 \mathrm{ng} / \mathrm{ml})$ or $\left[\mathrm{D}-\operatorname{Tr}^{7,9,10}\right.$ ]-Substance $\left.\mathrm{P}\left(10^{-5} \mathrm{M}\right)\right]$, of sarco/endoplasmic reticulum calcium transport ATPase [thapsigargin $\left(10^{-6} \mathrm{M}\right)$ ], of soluble guanylyl cyclase [ODQ $\left(10^{-5} \mathrm{M}\right)$ ] or of protein kinases [Rp-8-Br-cAMPs $\left(10^{-4} \mathrm{M}\right)$ or KT5823 $\left.\left(10^{-6} \mathrm{M}\right)\right]$ (Table 1).

\subsubsection{Indirect effects}

In the aorta or mesenteric and femoral arteries with endothelium, 30 min of incubation with $T_{3}$ $\left(10^{-7} \mathrm{M}\right)$ did not significantly affect phenylephrine-induced contractions or acetylcholine-induced relaxations (Fig. 2).

\subsection{Diabetic rats}

\subsubsection{General conditions}

Four weeks after the last streptozotocin injection, the body weight was significantly lower and the blood glucose level significantly increased in both $T_{3}$ and vehicle treated diabetic rats; there were no significant differences between the two groups as concerns those two parameters (Table 2). After four weeks of chronic $T_{3}$ treatment, the total $T_{3}$ serum level was significantly greater than that in the vehicle treated diabetic group (Table 2).

\subsubsection{Vascular responsiveness}

\subsubsection{Endothelium-dependent relaxations}

In the aorta and mesenteric arteries of vehicle treated diabetic rats, there was no impairment of relaxations to the endothelium-dependent vasodilator acetylcholine when compared with the 
age-matched normal SD rats (Fig. 3). Chronic treatment with $T_{3}$ did not affect the reference contractions to $60 \mathrm{mM} \mathrm{KCL}$ in aortic $[3.22 \pm 0.15$ and $3.15 \pm 0.19$ gram in rings from vehicle and hormone-treated rats, respectively], mesenteric [2.31 \pm 0.04 and $2.42 \pm 0.13$ gram, respectively] preparations and did not affect acetylcholine-induced relaxations significantly either (Fig. 3).

\subsubsection{Endothelium-dependent contractions}

These experiments were performed in preparations incubated with the NOS inhibitor L-NAME $\left(3 \times 10^{-4} \mathrm{M}\right)$, in order to optimize endothelium-dependent contractions (Auch-Schwelk et al., 1992;

Tang et al., 2005a). In the femoral artery of vehicle treated diabetic rats , A23187 (10-8 to $\left.10^{-6} \mathrm{M}\right)$ caused concentration-dependent contractions which were significantly larger in preparations with than in those without endothelium; the difference between the two types of preparations was reduced significantly by incubation with indomethacin $\left(5 \times 10^{-6} \mathrm{M}\right)$ or $\mathrm{S} 18886\left(10^{-7} \mathrm{M}\right)$ (Fig. 4 and Fig. 5, Left). Thirty min of incubation with $\mathrm{T}_{3}\left(10^{-7} \mathrm{M}\right)$ did not significantly affect A23187-induced contractions in rings with endothelium (Fig. 4). After four weeks of chronic treatment with $T_{3}$, there was no significant difference in the response to the ionophore between preparations with and without endothelium. The A23187 induced contractions in rings without endothelium were significantly larger in arteries from rats treated chronically with $T_{3}$ than in those from vehicle-treated animals; the augmented contraction to the ionophore in the former was abolished by incubation with indomethacin or S18886 (Fig. 5, Right). Chronic treatment with $\mathrm{T}_{3}$ did not affect the reference contractions to $60 \mathrm{mM} \mathrm{KCL}$ in femoral preparations with and without endothelium. 


\subsubsection{Endothelium-independent contractions}

In femoral artery rings without endothelium, both phenylephrine $\left(10^{-9}\right.$ to $\left.10^{-5} \mathrm{M}\right)$ and $\mathrm{U} 46619$ $\left(10^{-9}\right.$ to $\left.10^{-7} \mathrm{M}\right)$ evoked concentration-dependent contractions. There was no significant difference in phenylephrine-induced contraction between preparations of $T_{3}$ and vehicle treated diabetic rats (Fig. 6, Left). However, the concentration-response curve to the TP-agonist was shifted significantly to the left (Fig. 6, Right) in arteries from $\mathrm{T}_{3}$ treated animals (Table 3).

\subsubsection{Release of prostanoids}

A23187 evoked the release of 6-keto prostaglandin $F_{1 \alpha}$ and thromboxane $B_{2}$, in femoral arteries of both vehicle and $T_{3}$ treated diabetic rats. The release of the two prostanoids was significantly less in rings without than in those with endothelium. The production of 6-keto prostaglandin $F_{1 \alpha}$ was comparable in preparations with endothelium of $\mathrm{T}_{3}$ and vehicle treated diabetic rats (Fig. 7, Left). A significantly lower release of thromboxane $B_{2}$ (by $38.1 \pm 9.2 \%$ ) was observed in the rings with, but not in those without endothelium, of $T_{3}$ compared to vehicle treated animals (Fig. 7, Right).

\subsubsection{Protein expression}

\subsubsection{Arteries}

Four weeks after the injection of streptozotocin, the protein level of eNOS and COX-1 were significantly greater in preparations with than in those without endothelium of both $T_{3}$ and vehicle treated diabetic rats. The expression of eNOS $(140 \mathrm{kDa})$ was significantly increased by $227.5 \pm 24.1 \%$ (Fig. $8, \boldsymbol{A}$ ) but that of COX-1 $(72 \mathrm{kDa}$ ) was significantly reduced by $34.9 \pm 7.4 \%$ (Fig. 8, B) in preparations with endothelium of $T_{3}$ treated diabetic rats. The expression level of COX-2 
$(72 \mathrm{kDa})$ was similar among the different groups (Fig. 8, C). In femoral artery rings without endothelium, the protein levels of TP receptors $(55 \mathrm{kDa})$ were not significantly different between $\mathrm{T}_{3}$ and vehicle treated diabetic rats (Fig. 8, D).

\subsubsection{Cell culture}

Acute (30 min) or more prolonged (one or seven days) exposure to $T_{3}\left(10^{-10}\right.$ to $\left.10^{-7} \mathrm{M}\right)$, did not significantly affect the protein levels of eNOS, or COX-1 in quiescent HUVECs (data not shown). COX-2 was not detectable in either vehicle or $T_{3}$ treated unstimulated HUVECs (data not shown). Incubation of HUVECs with IL-1 $(1 \mathrm{ng} / \mathrm{ml}$; for one or seven days) induced a weak protein expression of COX-2, which was not different between vehicle and $T_{3}$ treated cells. When combined with IL-1 $\beta$, incubation with $T_{3}\left(10^{-10}\right.$ to $10^{-7} \mathrm{M}$, one day) did not significantly affect the protein levels of eNOS or those of either COX-1 or COX-2 (data not shown); however, co-incubation with IL-1 $\beta$ for seven days resulted in a significant, concentration-dependent increase in the protein content of eNOS without changes in those of COX-1 or COX-2 (Fig. 9).

\section{Discussion}

The present study determined the direct effect of thyroid hormone in arteries of different size of normal rats. The hormone did not relax the aorta, a conduit artery, but did so in smaller femoral and mesenteric arteries, implying that its direct vasodilator effect may be more important in resistance vessels. To judge from the similar relaxations observed in presence and absence of endothelium, the effect of the hormone is endothelium-independent, a conclusion consistent 
with previous studies (Ishikawa et al., 1989; Park et al., 1997). This direct vasodilator effect of $T_{3}$ in smaller arteries may help to explain why systemic vascular resistance is closely linked to the thyroid status in patients (Klein and Ojamaa, 2001). The present study explored, using accepted pharmacological inhibitors, a variety of possible explanations for the direct vasodilator properties of thyroid hormone. However, the actual underlying mechanism remained elusive. One unexplored possibility is acute inhibition of the transmembrane conductance regulator chloride channel, although the lack of effect of glibenclamide makes this unlikely (Cai, 2013; Fong, 2013).

To investigate whether or not $T_{3}$ modifies endothelial dysfunction, rats with streptozotocin-induced diabetes were exposed chronically to the hormone. Streptozotocin destroys $\beta$ cells of the Langerhans islets, reducing insulin release (Junod et al., 1969). The lower body weight and the higher blood glucose levels demonstrate the successful development of diabetes. The present experiments do not confirm in mice with type 1 diabetes the attenuation of hyperglycemia, observed in $\mathrm{db} / \mathrm{db}$ mice - with chronic $\mathrm{T}_{3}$ treatment, attributed to improved insulin signaling rather than increased production of the hormone (Lin and Sun, 2011).

Diabetic endothelial dysfunction (De Vriese et al., 2000; Shi et al., 2007a; Stehouwer et al., 1997), is characterized in type 1 diabetes by occurrence of endothelium-dependent contractions (Shi et al., 2007a). The present study confirms the absence of impaired endothelium-dependent relaxations to acetylcholine in arteries of rats at an early stage of diabetes (Shi et al., 2006; Shi and Vanhoutte, 2009). Impairment of acetylcholine-induced relaxations can occur in arteries such as used in the present study after longer exposure to (Cameron and Cotter, 1992; Fukao et 
al., 1997; Pieper and Peltier, 1995; Shimizu et al., 1993), or with higher doses of (Palmer et al., 1998; Pieper et al., 1997; Taylor et al., 1994) streptozotocin, or in skeletal muscle (Hill and Ege, 1994) and basilar (Mayhan and Patel, 1998) arteries. The present absence of effect of chronic $T_{3}$ treatment on relaxations to acetylcholine contrasts with the augmentation observed in the aorta and femoral artery of normoglycemic animals (Deng et al., 2010). In the latter study, the relaxations to acetylcholine were also studied during phenylephrine contractions, but the response to the $\alpha_{1}$-adrenergic agonist was reduced by hyperthyroidism, which was not the case in our experiments. Functional antagonists such as endothelium-derived or exogenous nitric oxide are more effective in causing relaxation against weaker pre-contraction levels (Flavahan and Vanhoutte, 1988).

Acetylcholine induces endothelium-dependent contractions in aorta of spontaneously hypertensive (SHR) and normotensive rats (Li et al., 2011; Tang et al., 2005b). However, it does not evoke such responses in femoral arteries of SD rats whereas the calcium ionophore A23187 does (Shi et al., 2007a; Shi et al., 2007b). Streptozotocin-induced diabetes exacerbates such EDCF-mediated responses (Shi et al., 2007a). Therefore, the present study focused on A23187 responses in the femoral artery. The results confirm that it elicits endothelium-dependent contractions of this preparation from diabetic rats (Shi et al., 2007a). This endothelium-dependent contraction was abolished by indomethacin [a nonspecific cyclooxygenases (COX) inhibitor] or S18886 [a specific TP receptor antagonist], confirming that A23187 releases COX-derived EDCF (Lüscher and Vanhoutte, 1986; Tang et al., 2007; Wong et al., 2010a) and that these factors activate TP receptors of the underlying vascular smooth muscle 
(Auch-Schwelk et al., 1990; Tang and Vanhoutte, 2009). In the SHR aorta, A23187 releases both prostacyclin and thromboxane $A_{2}$ as EDCF, and the latter is the most potent TP receptor agonist (Gluais et al., 2005; Gluais et al., 2006). The present results confirm that A23187 augments the endothelial production of 6-keto prostaglandin $F_{1 \alpha}$ and thromboxane $B_{2}$. After four weeks of $T_{3}$ treatment, no difference in contraction to $\mathrm{A} 23187$ was observed between preparations with and without endothelium, implying that the hormone reduces EDCF release. This interpretation is strengthened by the lesser endothelial production of thromboxane $B_{2}$ in arteries of diabetic rats. $T_{3}$, through changes in gene transcription, increases the number of calcium-activated ATPase pump units in the sarcoplasmic reticulum and thus causes more efficient pumping by the calcium-activated ATPase (Dillmann, 1990). If this were to occur in the endothelium of diabetic rats, increased activity of calcium-activated ATPase may counteract the effect of A23187 on the COX-1 axis, reducing EDCF release.

The difference of COX-1 level between preparations with and without endothelium in $\mathrm{T}_{3}$ and vehicle treated diabetic rats, is in line with the importance of endothelial COX-1 for the occurrence of endothelium-dependent contractions (Tang and Vanhoutte, 2010). The absence of difference in COX-2 level confirms that COX-1 plays the prominent role in endothelial dysfunction in rodents (Ge et al., 1995; Shi et al., 2008; Tang et al., 2005b). However, a lower COX-1 level was observed in $T_{3}$ treated diabetic rats, which also fits with the lower production of thromboxane $B_{2}$ by the endothelial cells of arteries chronically exposed to the hormone.

Chronic inflammation is involved in the pathogenesis of type 1 diabetes, and contributes to the 
inhibition of growth and function of the $\beta$ cells of the pancreas (Eizirik et al., 2009; Wellen and Hotamisligil, 2005). Conversely, diabetes-induced increases in oxidative stress augment the release of pro-inflammatory cytokines sustaining the inflammatory state (Zhang et al. 2003). In addition, the inflammatory mediators may accelerate the onset of endothelial dysfunction in type 1 diabetes (Goldberg, 2009; Stehouwer et al., 1997). Hence, to mimic the chronic impact of diabetes on endothelial cells, cultures of HUVECs were exposed to IL-1 $\beta$, a cytokine involved in the pathology of the disease (Liu et al., 2012; Mandrup-Poulsen et al., 2010; Reimers, 1998). In the present study, prolonged exposure to the hormone on a background of IL-1 $\beta$ stimulation, caused the expected expression of COX-2 (Uracz et al., 2002), but also increased the protein level of eNOS, a finding in line with the present observations in arteries of $\mathrm{T}_{3}$-treated diabetic rats. Thus, the inflammatory response that accompanies diabetes (Wellen and Hotamisligil, 2005) may be required for the expression of a chronic augmentation in eNOS caused by thyroid hormone. The resulting increase in NO bioavailability would explain the curtailment of endothelium-dependent contractions (Tang et al., 2005a). Taken in conjunction, the present findings permit to conclude that chronic treatment with $T_{3}$ of rats with type 1 diabetes attenuates the release of EDCF by augmenting total eNOS and reducing the presence and/or activity of cyclooxygenase in their endothelial cells. Since acute exposure to $T_{3}$ did not affect endothelium-dependent contractions to A23187, the effect of the long-term treatment with the hormone is genomic in nature.

The absence of difference in the response to phenylephrine between femoral arteries of the $T_{3}$ and vehicle treated groups, contrasts with the reduction observed in normoglycemic rats (Deng 
et al., 2010). We have no explanation for this discrepancy. However the findings obtained under our experimental conditions imply that $T_{3}$ has no effect on $\alpha$-adrenoceptors and does not chronically increase the intrinsic responsiveness of vascular smooth muscle in arteries of diabetic rats. By contrast, since no changes in the protein presence of TP receptors were obvious, the augmented contractions and the shift to the left of the concentration-response curve to the prototypical TP agonist U44169 (Gluais et al., 2005) imply that chronic treatment with $T_{3}$ increases the sensitivity of these receptors. Hence, chronic $T_{3}$ treatment in diabetic rats also augmented contractions to A23187 in preparations without endothelium. Since this augmented contraction was abolished by indomethacin and S18886 (implying that A23187 triggers the COX-mediated pathway in vascular smooth muscle), it must be due to activation of TP receptors and is explained by the hyperresponsiveness of the TP receptors. The present experiments do not permit to speculate further on the molecular mechanism underlying this phenomenon. In terms of relevance for the in vivo situation, any increase in TP receptor responsiveness would be offset by the reduced release in endothelium-derived vasoconstrictor prostanoids.

In summary, the present study demonstrates that, administered in vitro in pharmacological high concentrations, $T_{3}$ acutely relaxes mesenteric and femoral vascular smooth muscle of normal rats but does so in an endothelium-independent manner. The mechanism underlying this direct relaxing effect remains elusive, as is its importance in vivo. In type 1 diabetic rats, while chronic in vivo $\mathrm{T}_{3}$ treatment with pathophysiological relevant doses can reduce the ex vivo release of EDCF (an interpretation confirmed by the measurement of prostanoid release and explained by the reduced expression of COX-1 and the increased presence of eNOS), it increases the sensitivity of 
TP receptors of vascular smooth muscle (Fig. 10). Thus, thyroid hormone can affect both endothelial and vascular smooth muscle cells in rat arteries. 


\section{Grants}

This research was supported by The University of Hong Kong, Research Grant Council of the Hong

Kong Special Administrative Region Grant HKU777208M, and World Class University Program Grant R31-20029, funded by the Ministry of Education, Science and Technology (South Korea).

\section{Disclosures}

The authors declare no conflicts of interest, financial or otherwise.

\section{Author contributions}

Designed the experiments: Yin Cai, Eva H.C. Tang, Paul M. Vanhoutte. Performed the experiments:

Yin Cai, Michael M. Manio. Analyzed the data: Yin Cai, George P.H. Leung, Aimin Xu, Eva H.C. Tang, Paul M. Vanhoutte. Wrote the paper: Yin Cai, Eva H.C. Tang, Paul M. Vanhoutte. 


\section{References}

Auch-Schwelk, W., Katusic, Z.S., Vanhoutte, P.M., 1992. Nitric oxide inactivates endothelium-derived contracting factor in the rat aorta. Hypertension 19, 442-445.

Auch-Schwelk, W., Katusic, Z.S., Vanhoutte, P.M., 1990. Thromboxane A2 receptor antagonists inhibit endothelium-dependent contractions. Hypertension 15, 699-703.

Cai, Z., Li, H., Chen, J.H., Sheppard, D.N., 2013. Acute inhibition of the cystic fibrosis transmembrane conductance regulator (CFTR) Cl-channel by thyroid hormones involves multiple mechanisms. Am. J. Physiol. Cell Physiol. 305, C817-C828.

Cameron, N.E., Cotter, M.A., 1992. Impaired contraction and relaxation in aorta from streptozotocin-diabetic rats: role of polyol pathway. Diabetologia 35, 1011-1019.

Carrillo-Sepúlveda, M.A., Ceravolo, G.S., Fortes, Z.B., Carvalho, M.H., Tostes, R.C., Laurindo, F.R., Webb, R.C., Barreto-Chaves, M.L., 2010. Thyroid hormone stimulates NO production via activation of the PI3K/Akt pathway in vascular myocytes. Cardiovasc. Res. 85, 560-570.

Chambliss, K.L., Shaul, P.W., 2002. Estrogen Modulation of Endothelial Nitric Oxide Synthase. Endocr. Rev. 23, 665-686.

Chan, C.K., Mak, J., Gao, Y., Man, R.Y., Vanhoutte, P.M., 2011. Endothelium-derived NO, but not cyclic GMP, is required for hypoxic augmentation in isolated porcine coronary arteries. Am. J. Physiol. Heart Circ. Physiol. 301, H2313-H2321.

Cognard, C., Rivet, M., Raymond, G., 1990. The blockade of excitation/contraction coupling by nifedipine in patch-clamped rat skeletal muscle cells in culture. Pflugers Arch. 416, 98-105.

De Vriese, A.S., Verbeuren, T.J., Van de Voorde, J., Lameire, N.H., Vanhoutte, P.M., 2000. Endothelial dysfunction in diabetes. Br. J. Pharmacol. 130, 963-974. 
Deng, J., Zhao, R., Zhang, Z., Wang, J., 2010. Changes in vasoreactivity of rat large- and medium-sized arteries induced by hyperthyroidism. Exp. Toxicol. Pathol. 62, 317-322.

Dillmann, W.H., 1990. Biochemical basis of thyroid hormone action in the heart. Am. J. Med. 88, 626-630.

Dillmann, W.H., 1982. Influence of thyroid hormone administration on myosin ATPase activity and myosin isoenzyme distribution in the heart of diabetic rats. Metabolism 31, 199-204.

Edwards, G., Dora, K.A., Gardener, M.J., Garland, C.J., Weston, A.H., 1998. $\mathrm{K}^{+}$is an endothelium-derived hyperpolarizing factor in rat arteries. Nature 396, 269-272.

Eizirik, D.L., Colli, M.L., Ortis, F., 2009. The role of inflammation in insulitis and beta-cell loss in type 1 diabetes. Nat. Rev. Endocrinol. 5, 219-226.

Félétou, M., Vanhoutte, P.M., 2007. Endothelium-dependent hyperpolarizations: past beliefs and present facts. Ann. Med. 39, 495-516.

Félétou, M., Vanhoutte, P.M., 2006. Endothelium-Derived Hyperpolarizing Factor: Where Are We Now? Arterioscler. Thromb. Vasc. Biol. 26, 1215-1225.

Flavahan, N.A., Vanhoutte, P.M., 1988. Receptor-reserve and heterogeneity of vascular responses to vasodilator stimuli. In: Vanhoutte, P.M. (Ed), Mechanisms of Vasodilation. Raven Press, New York, pp. 201-210.

Fong, P., 2013. Time for T...(T3, T4, rT3)? Focus on "Acute inhibition of the cystic fibrosis transmembrane conductance regulator (CFTR) Cl- channel by thyroid hormones involves multiple mechanisms". Am. J. Physiol. Cell Physiol. 305, C800-C802.

Fukao, M., Hattori, Y., Kanno, M., Sakuma, I., Kitabatake, A., 1997. Alterations in endothelium-dependent hyperpolarization and relaxation in mesenteric arteries from 
streptozotocin-induced diabetic rats. Br. J. Pharmacol. 121, 1383-1391.

Furchgott, R.F., Vanhoutte, P.M., 1989. Endothelium-derived relaxing and contracting factors. FASEB J. 3, 2007-2018.

Furchgott, R.F., Zawadzki, J.V., 1980. The obligatory role of endothelial cells in the relaxation of arterial smooth muscle by acetylcholine. Nature $288,373-376$.

Ge, T., Hughes, H., Junquero, D.C., Wu, K.K., Vanhoutte, P.M., Boulanger, C.M. 1995. Endothelium-dependent contractions are associated with both augmented expression of prostaglandin $\mathrm{H}$ synthase-1 and hypersensitivity to prostaglandin $\mathrm{H} 2$ in the SHR Aorta. Circ. Res. 76, 1003-1010.

Gisclard, V., Miller, V.M., Vanhoutte, P.M., 1988. Effect of 17 beta-estradiol on endothelium-dependent responses in the rabbit. J. Pharmacol. Exp. Ther. 244, 19-22.

Gluais, P., Lonchampt, M., Morrow, J.D., Vanhoutte, P.M., Félétou, M., 2005. Acetylcholine-induced endothelium-dependent contractions in the SHR aorta: the Janus face of prostacyclin. Br. J. Pharmacol. 146, 834-845.

Gluais, P., Paysant, J., Badier-Commander, C., Verbeuren, T., Vanhoutte, P.M., Félétou, M., 2006. In SHR aorta, calcium ionophore A-23187 releases prostacyclin and thromboxane A2 as endothelium-derived contracting factors. Am. J. Physiol. Heart Circ. Physiol. 291, H2255-H2264.

Goldberg R.B., 2009. Cytokine and cytokine-like inflammation markers, endothelial dysfunction, and imbalanced coagulation in development of diabetes and its complications. J. Clin. Endocrinol. Metab. 94, 3171-3182.

Hage, M., Zantout, M.S., Azar, S.T., 2011. Thyroid Disorders and Diabetes Mellitus. J. Thyroid Res. $2011,439463$. 
Hill, M.A., Ege, E.A., 1994. Active and passive mechanical properties of isolated arterioles from STZ-induced diabetic rats: effect of aminoguanidine treatment. Diabetes 43, 1450-1456.

Hiroi, Y., Kim, H.H., Ying, H., Furuya, F., Huang, Z., Simoncini, T., Noma, K., Ueki, K., Nguyen, N.H., Scanlan, T.S., Moskowitz, M.A., Cheng, S.Y., Liao, J.K., 2006. Rapid nongenomic actions of thyroid hormone. Proc. Natl. Acad. Sci. USA 103, 14104-14109.

Ichiki, T., 2010. Thyroid hormone and atherosclerosis. Vascul. Pharmacol. 52, 151-156.

Ishikawa, T., Chijiwa, T., Hagiwara, M., Mamiya, S., Hidaka, H., 1989. Thyroid hormones directly interact with vascular smooth muscle strips. Mol. Pharmacol. 35, 760-765.

Junod, A., Lambert, A.E., Stauffacher, W., Renold, A.E., 1969. Diabetogenic action of streptozotocin: relationship of dose to metabolic response. J. Clin. Invest. 48, 2129-2139.

Katusic, Z.S., Shepherd, J.T., Vanhoutte, P.M., 1986. Oxytocin causes endothelium-dependent relaxations of canine basilar arteries by activating V1-vasopressinergic receptors. J. Pharmacol. Exp. Ther. 236, 166-170.

Katusic, Z.S., Shepherd, J.T., Vanhoutte, P.M., 1984. Vasopressin causes endothelium-dependent relaxations of the canine basilar artery. Circ. Res. 55, 575-579.

Keung, W., Vanhoutte, P.M., Man, R.Y., 2005. Acute impairment of contractile responses by $17 \beta$-estradiol is cAMP and protein kinase $\mathrm{G}$ dependent in vascular smooth muscle cells of the porcine coronary arteries. Br. J. Pharmacol. 144, 71-79.

Klein, I., Ojamaa, K., 2001. Thyroid Hormone and the cardiovascular system. N. Engl. J. Med. 344, 501-509.

Lekakis, J., Papamichael, C., Alevizaki, M., Piperingos, G., Marafelia, P., Mantzos, J., Stamatelopoulos, S., Koutras, D.A., 1997. Flow-mediated, endothelium-dependent vasodilatation 
is impaired in subjects with hypothyroidism, borderline hypothyroidism, and high-normal serum thyrotropin (TSH) values. Thyroid 7, 411-414.

Li, Z., Wang, Y., Man, R.Y., Vanhoutte, P.M., 2013. Upregulation of heme oxygenase-1 potentiates EDH-type relaxations in the mesenteric artery of the spontaneously hypertensive rat. Am. J. Physiol. Heart Circ. Physiol. 305, H1471-H1483.

Li, Z., Wang, Y., Vanhoutte, P.M., 2011. Upregulation of heme oxygenase 1 by hemin impairs endothelium-dependent contractions in the aorta of the spontaneously hypertensive rat. Hypertension 58, 926-934.

Lin, Y., Sun, Z., 2011. Thyroid hormone potentiates insulin signaling and attenuates hyperglycemia and insulin resistance in a mouse model of type 2 diabetes. Br. J. Pharmacol. 162, 597-610.

Liu, J.T., Song, E., Xu, A., Berger, T., Mak, T.W., Tse, H.F., Law, I.K., Huang, B., Liang, Y., Vanhoutte, P.M., Wang, Y., 2012. Lipocalin-2 deficiency prevents endothelial dysfunction associated with dietary obesity: role of cytochrome P450 2C inhibition. Br. J. Pharmacol. 165, 520-531.

Liu, Y., Biarnés Costa, M., Gerhardinger, C., 2012. IL-1ß is upregulated in the diabetic retina and retinal vessels: cell-specific effect of high glucose and IL-1 $\beta$ autostimulation. PLoS One 7, e36949. Lüscher, T.F., Vanhoutte, P.M., 1986. Endothelium-dependent contractions to acetylcholine in the aorta of the spontaneously hypertensive rat. Hypertension 8, 344-348.

Mandrup-Poulsen, T., Pickersgill, L., Donath, M.Y., 2010. Blockade of interleukin 1 in type 1 diabetes mellitus. Nat. Rev. Endocrinol. 6, 158-166.

Mayhan, W.G., Patel, K.P., 1998. Treatment with dimethylthiourea prevents impaired dilatation of the basilar artery during diabetes mellitus. Am. J. Physiol. Heart Circ. Physiol. 274, H1895-H1901. Mukai, H., Munekata, E., Higashijima, T., 1992. G protein antagonists. A novel hydrophobic 
peptide competes with receptor for $\mathrm{G}$ protein binding. J. Biol. Chem. 267, 16237-16243.

Napoli, R., Biondi, B., Guardasole, V., Matarazzo, M., Pardo, F., Angelini, V., Fazio, S., Saccà, L., 2001. Impact of hyperthyroidism and its correction on vascular reactivity in humans. Circulation 104, 3076-3080.

Ojamaa, K., Klemperer, J.D., Klein, I., 1996. Acute Effects of Thyroid Hormone on Vascular Smooth Muscle. Thyroid 6, 505-512.

Palmer, A.M., Gopaul, N., Dhir, S., Thomas, C.R., Poston, L., Tribe, R.M., 1998. Endothelial dysfunction in streptozotocin-diabetic rats is not reversed by dietary probucol or simvastatin supplementation. Diabetologia 41, 157-164.

Park, K.W., Dai, H.B., Ojamaa, K., Lowenstein, E., Klein, I., Sellke, F.W., 1997. The direct vasomotor effect of thyroid hormones on rat skeletal muscle resistance arteries. Anesth. Analg. 85, 734-738. Pieper, G.M., Langenstroer, P., Siebeneich, W., 1997. Diabetic-induced endothelial dysfunction in rat aorta: role of hydroxyl radicals. Cardiovasc. Res. 34, 145-156.

Pieper, G.M., Peltier, B.A., 1995. Amelioration by L-arginine of a dysfunctional arginine/nitric oxide pathway in diabetic endothelium. J. Cardiovasc. Pharmacol. 25, 397-403.

Reimers, J.I., 1998. Interleukin-1 beta induced transient diabetes mellitus in rats. A model of the initial events in the pathogenesis of insulin-dependent diabetes mellitus? Dan. Med. Bull. 45, 157-180.

Shi, Y., Félétou, M., Ku, D.D., Man, R.Y., Vanhoutte, P.M., 2007a. The calcium ionophore A23187 induces endothelium-dependent contractions in femoral arteries from rats with streptozotocin-induced diabetes. Br. J. Pharmacol. 150, 624-632.

Shi, Y., Ku, D.D., Man, R.Y., Vanhoutte, P.M., 2006. Augmented endothelium-derived 
hyperpolarizing factor-mediated relaxations attenuate endothelial dysfunction in femoral and mesenteric, but not in carotid arteries from type I diabetic rats. J. Pharmacol. Exp. Ther. 318, 276-281.

Shi, Y., Man, R.Y., Vanhoutte, P.M., 2008. Two isoforms of cyclooxygenase contribute to augmented endothelium-dependent contractions in femoral arteries of 1-year-old rats. Acta Pharmacol. Sin. 29, 185-192.

Shi, Y., So, K.F., Man, R.Y., Vanhoutte, P.M., 2007b. Oxygen-derived free radicals mediate endothelium-dependent contractions in femoral arteries of rats with streptozotocin-induced diabetes. Br. J. Pharmacol. 152, 1033-1041.

Shi, Y., Vanhoutte, P.M., 2009. Reactive oxygen-derived free radicals are key to the endothelial dysfunction of diabetes. J. Diabetes 1, 151-162.

Shimizu, K., Muramatsu, M., Kakegawa, Y., Asano, H., Toki, Y., Miyazaki, Y., Okumura, K., Hashimoto, H., Ito, T., 1993. Role of prostaglandin H2 as an endothelium-derived contracting factor in diabetic state. Diabetes 42, 1246-1252.

Stehouwer, C.D., Lambert, J., Donker, A.J., van Hinsbergh, V.W., 1997. Endothelial dysfunction and pathogenesis of diabetic angiopathy. Cardiovasc. Res. 34, 55-68.

Szkudelski, T., Michalski, W., Szkudelska, K., 2003. The effect of thyroid hormones on blood insulin level and metabolic parameters in diabetic rats. J. Physiol. Biochem. 59, 71-76.

Taylor, P.D., Oon, B.B., Thomas, C.R., Poston, L., 1994. Prevention by insulin treatment of endothelial dysfunction but not enhanced noradrenaline-induced contractility in mesenteric resistance arteries from streptozotocin-induced diabetic rats. Br. J. Pharmacol. 111, 35-41.

Taddei, S., Caraccio, N., Virdis, A., Dardano, A., Versari, D., Ghiadoni, L., Salvetti, A., Ferrannini, E., 
Monzani, F., 2003. Impaired endothelium-dependent vasodilatation in subclinical hypothyroidism: beneficial effect of levothyroxine therapy. J. Clin. Endocr. Metab. 88, 3731-3737.

Tang, E.H., Félétou, M., Huang, Y., Man, R.Y., Vanhoutte, P.M., 2005a. Acetylcholine and sodium nitroprusside cause long-term inhibition of EDCF-mediated contractions. Am. J. Physiol. Heart Circ. Physiol. 289, H2434-H2440.

Tang, E.H., Ku, D.D., Tipoe, G.L., Félétou, M., Man, R.Y., Vanhoutte, P.M., 2005b. Endothelium-dependent contractions occur in the aorta of wild-type and $\mathrm{COX}^{-/-}$knockout but not $\mathrm{COX1}^{-/-}$knockout mice. J. Cardiovasc. Pharmacol. 46, 761-765.

Tang, E.H., Leung, F.P., Huang, Y., Félétou, M., So, K.F., Man, R.Y., Vanhoutte, P.M., 2007. Calcium and reactive oxygen species increase in endothelial cells in response to releasers of endothelium-derived contracting factor. Br. J. Pharmacol. 151, 15-23.

Tang, E.H., Vanhoutte, P.M., 2010. Endothelial dysfunction: a strategic target in the treatment of hypertension? Pflugers Arch. 459, 995-1004.

Tang, E.H., Vanhoutte, P.M., 2009. Prostanoids and reactive oxygen species: team players in endothelium-dependent contractions. Pharmacol. Ther. 122, 140-149.

Uracz, W., Uracz, D., Olszanecki, R., Gryglewski, R.J., 2002. Interleukin 1beta induces functional prostaglandin E synthase in cultured human umbilical vein endothelial cells. J. Physiol. Pharmacol. $53,643-654$.

Vanhoutte, P.M., 2011. Endothelium-dependent contractions in hypertension: when prostacyclin becomes ugly. Hypertension 57, 526-531.

Vanhoutte, P.M., 2004. Endothelium-dependent hyperpolarizations: the history. Pharmacol. Res. 49, 503-508. 
Vanhoutte, P.M., Miller, V.M., 1989. Alpha 2-adrenoceptors and endothelium-derived relaxing factor. Am. J. Med. 87, S1-S5.

Wellen, K.E., Hotamisligil, G.S., 2005. Inflammation, stress, and diabetes. J. Clin. Invest. 115, 1111-1119.

Weston, A.H., Absi, M., Harno, E., Geraghty, A.R., Ward, D.T., Ruat, M., Dodd, R.H., Dauban, P., Edwards, G., 2008. The expression and function of $\mathrm{Ca}^{2+}$-sensing receptors in rat mesenteric artery; comparative studies using a model of type II diabetes. Br. J. Pharmacol. 154, 652-662.

Wong, E.S., Man, R.Y., Vanhoutte, P.M., Ng, K.F., 2010. Dexmedetomidine induces both relaxations and contractions, via different $\alpha 2$-adrenoceptor subtypes, in the isolated mesenteric artery and aorta of the rat. J. Pharmacol. Exp. Ther. 335, 659-664.

Wong, M.S., Delansorne, R., Man, R.Y., Svenningsen, P., Vanhoutte, P.M., 2010a. Chronic treatment with vitamin D lowers arterial blood pressure and reduces endothelium-dependent contractions in the aorta of the spontaneously hypertensive rat. Am. J. Physiol. Heart Circ. Physiol. 299, H1226-H1234.

Wong, M.S., Delansorne, R., Man, R.Y., Vanhoutte, P.M., 2008. Vitamin D derivatives acutely reduce endothelium-dependent contractions in the aorta of the spontaneously hypertensive rat. Am. J. Physiol. Heart Circ. Physiol. 295, H289-H296.

Wong, M.S., Man, R.Y., Vanhoutte, P.M., 2010b. Calcium-independent phospholipase A2 plays a key role in the endothelium-dependent contractions to acetylcholine in the aorta of the spontaneously hypertensive rat. Am. J. Physiol. Heart Circ. Physiol. 298, H1260-H1266.

Wong, M.S., Vanhoutte, P.M., 2010c. COX-mediated endothelium-dependent contractions: from the past to recent discoveries. Acta Pharmacol. Sin. 31, 1095-1102. 
Yen, P.M., 2001. Physiological and molecular basis of thyroid hormone action. Physiol. Rev. 81, 1097-1142.

Zhang, F.J., Ma, L.L., Wang, W.N., Qian, L.B., Yang, M.J., Yu, J., Chen, G., Yu, L.N., Yan, M., 2012. Hypercholesterolemia abrogates sevoflurane-induced delayed preconditioning against myocardial infarct in rats by alteration of nitric oxide synthase signaling. Shock 37, 485-491.

Zhang, L., Zalewski, A., Liu, Y., Mazurek, T., Cowan, S., Martin, J.L., Hofmann, S.M., Vlassara, H., Shi, Y., 2003. Diabetes-induced oxidative stress and low-grade inflammation in porcine coronary arteries. Circulation 108, 472-478. 


\section{Legends}

\section{Fig. 1}

Effects of increasing concentrations of $\mathrm{T}_{3}$ (five $\mathrm{min} /$ dose) on contractions of rat arteries with [+EC] or without $[-\mathrm{EC}]$ endothelium during sustained contractions to U46619 $\left(3 \times 10^{-8} \mathrm{M}\right)$. Data expressed as percentage of the pre-contraction to U46619 [100\%: aorta, $3.64 \pm 0.23 \mathrm{~g}$; mesenteric arteries, $2.38 \pm 0.25 \mathrm{~g}$; femoral arteries, $2.04 \pm 0.17 \mathrm{~g}$ ] and shown as means \pm S.E.M.; $n=4 .{ }^{*}$ Statistically significant difference between preparations of vehicle and $T_{3}$ groups $(P<0.05)$.

\section{Fig. 2}

Effect of incubation with $\mathrm{T}_{3}\left(10^{-7} \mathrm{M}, 30 \mathrm{~min}\right)$ on responses of rat arteries with endothelium. Left: contractions of quiescent preparations to increasing concentrations of phenylephrine. Data expressed as percentage of the pre-contraction to $\mathrm{KCL}[100 \%$ : aorta, $3.52 \pm 0.14 \mathrm{~g}$; mesenteric arteries, $2.27 \pm 0.32 \mathrm{~g}$; femoral arteries, $2.24 \pm 0.35 \mathrm{~g}$ ] and shown as means \pm S.E.M.; Right: relaxations to increasing concentrations of acetylcholine during sustained contractions to phenylephrine $\left(10^{-6} \mathrm{M}\right)$. Data expressed as percentage of the pre-contraction to phenylephrine [100\%: aorta, 3.45 $\pm 0.19 \mathrm{~g}$; mesenteric arteries, $2.12 \pm 0.34 \mathrm{~g}$; femoral arteries, $2.15 \pm 0.26 \mathrm{~g}]$ and shown as means \pm S.E.M.; $n=4$.

\section{Fig. 3}

Relaxations to cumulative concentrations of acetylcholine during sustained contractions to phenylephrine $\left(10^{-6} \mathrm{M}\right)$, in aorta and mesenteric arteries with endothelium from normal rats, vehicle and $T_{3}$ treated diabetic rats. Data expressed as percentage of the pre-contraction to phenylephrine [100\%: vehicle treated diabetic rats, aorta, $3.36 \pm 0.27 \mathrm{~g}$, mesenteric arteries, $2.08 \pm 0.20 \mathrm{~g} ; T_{3}$ treated diabetic rats, aorta, $3.22 \pm 0.41 \mathrm{~g}$, mesenteric arteries, $\left.2.29 \pm 0.25 \mathrm{~g}\right]$ and 
shown as means \pm S.E.M.; $n=4$.

\section{Fig. 4}

Responses, in the presence of L-NAME $\left(3 \times 10^{-4} \mathrm{M}\right)$ or L-NAME $\left(3 \times 10^{-4} \mathrm{M}\right)$ plus $\mathrm{T}_{3}\left(10^{-7} \mathrm{M}, 30 \mathrm{~min}\right)$, to cumulative concentrations of $\mathrm{A23187}$, in femoral arteries with (+EC) or without (-EC) from diabetic rats. Data expressed as percentage of the pre-contraction to $K C L$ [100\%: with endothelium, $2.03 \pm 0.32 \mathrm{~g}$; without endothelium, $1.98 \pm 0.28 \mathrm{~g}]$ and shown as means \pm S.E.M.; $n=5$.

\section{Fig. 5}

Responses, in the presence of L-NAME $\left(3 \times 10^{-4} \mathrm{M}\right)$, to cumulative concentrations of A23187, with or without indomethacin $\left(5 \times 10^{-6} \mathrm{M}\right)$ or $\mathrm{S} 18886\left(10^{-7} \mathrm{M}\right)$, in femoral arteries with $(+\mathrm{EC})$ or without (-EC) from vehicle (Left) and $\mathrm{T}_{3}$ (Right) treated diabetic rats. Data expressed as percentage of the pre-contraction to $\mathrm{KCL}$ [100\%: vehicle treated diabetic rats, with endothelium, $2.03 \pm 0.32 \mathrm{~g}$; without endothelium, $1.98 \pm 0.28 \mathrm{~g} ; \mathrm{T}_{3}$ treated diabetic rats, with endothelium, $2.05 \pm 0.18 \mathrm{~g}$; without endothelium, $2.12 \pm 0.33 \mathrm{~g}$ ] and shown as means \pm S.E.M.; $\mathrm{n}=10$ to 15 . ${ }^{*}$ Statistically significant difference between preparations with and without endothelium $(P<0.05)$. "Statistically significant difference between preparations in the presence and absence of indomethacin or S18886 $(P<0.05)$

\section{Fig. 6}

Responses to cumulative concentrations of phenylephrine (Left) and U46619 (Right) in rings of femoral arteries without endothelium from $T_{3}$ and vehicle treated diabetic rats. Data expressed as percentage of the pre-contraction to $\mathrm{KCL}\left[100 \%\right.$ : vehicle treated diabetic rats, $1.98 \pm 0.28 \mathrm{~g} ; \mathrm{T}_{3}$ treated diabetic rats, $2.12 \pm 0.33 \mathrm{~g}$ ] and shown as means \pm S.E.M.; $n=5$ to 10 . "Statistically 
significant difference between arteries of vehicle and $T_{3}$ treated diabetic rats $(P<0.05)$.

Fig. 7

Release of 6-keto prostaglandin $\mathrm{F}_{1 \alpha}\left(\right.$ Left) and thromboxane $\mathrm{B}_{2}$ (Right) in response to A23187 $\left(10^{-6} \mathrm{M}\right)$ in femoral arterial rings with $(+\mathrm{EC})$ and without $(-\mathrm{EC})$ endothelium from $\mathrm{T}_{3}$ and vehicle treated diabetic rats. Data shown as means \pm S.E.M.; $n=8$ to 12 . ${ }^{*}$ Statistically significant difference between preparations with and without endothelium $(P<0.05)$; "Statistically significant difference between preparations of vehicle and $T_{3}$ treated diabetic rats $(P<0.05)$.

\section{Fig. 8}

Western blotting analysis of the protein expression of eNOS (A), COX-1 (B), COX-2 (C) and TP receptor (D) in femoral arterial rings from vehicle and $T_{3}$ treated diabetic rats. Data shown as means \pm S.E.M.; $n=3$. "Statistically significant difference between preparations with and without endothelium ( $P<0.05)$; " statistically significant difference between arteries of vehicle and $T_{3}$ treated diabetic rats $(P<0.05)$. All the samples were derived at the same time and processed in parallel.

\section{Fig. 9}

Western blotting analysis of the protein expression of eNOS, COX-1 and COX-2 in HUVECs stimulated with $\mathrm{T}_{3}\left(10^{-10}\right.$ to $\left.10^{-7} \mathrm{M}\right)$ for one week in the presence of IL-1 $\beta(1 \mathrm{ng} / \mathrm{ml})$. Data shown as means \pm S.E.M.; $n=3$. "Statistically significant difference between preparations of vehicle and $T_{3}$ treated groups.

\section{Fig. 10}

In arteries of diabetic rat, A23187 elicits endothelium-dependent contractions, which can be abolished by indomethacin or S18886. After chronic $\mathrm{T}_{3}$ treatment, the release of EDCF is reduced, 
which could be due to the increased expression of eNOS and/or the reduced presence of COX-1.

$T_{3}$ treatment increases the sensitivity of TP receptors of the vascular smooth muscle, which lead to the comparable contractions to A23187 in preparations with and without endothelium. The presence of indomethacin or S18886 can block A23187 induced contractions in preparations without endothelium. 
Fig. 1
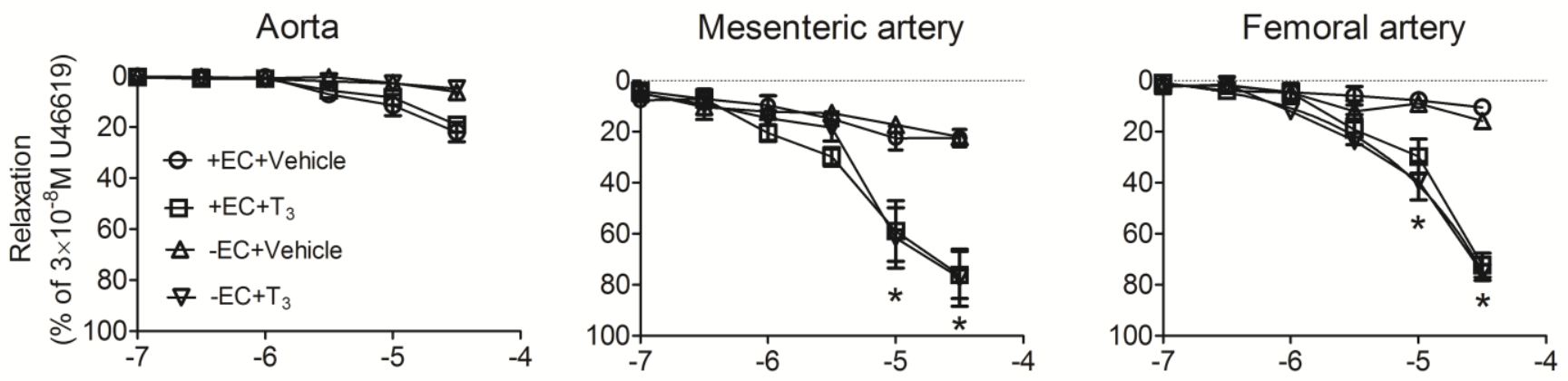

$\mathrm{T}_{3}$ or Vehicle (Log $\left.\mathrm{M}\right)$ 
Fig. 2

\section{Aorta}

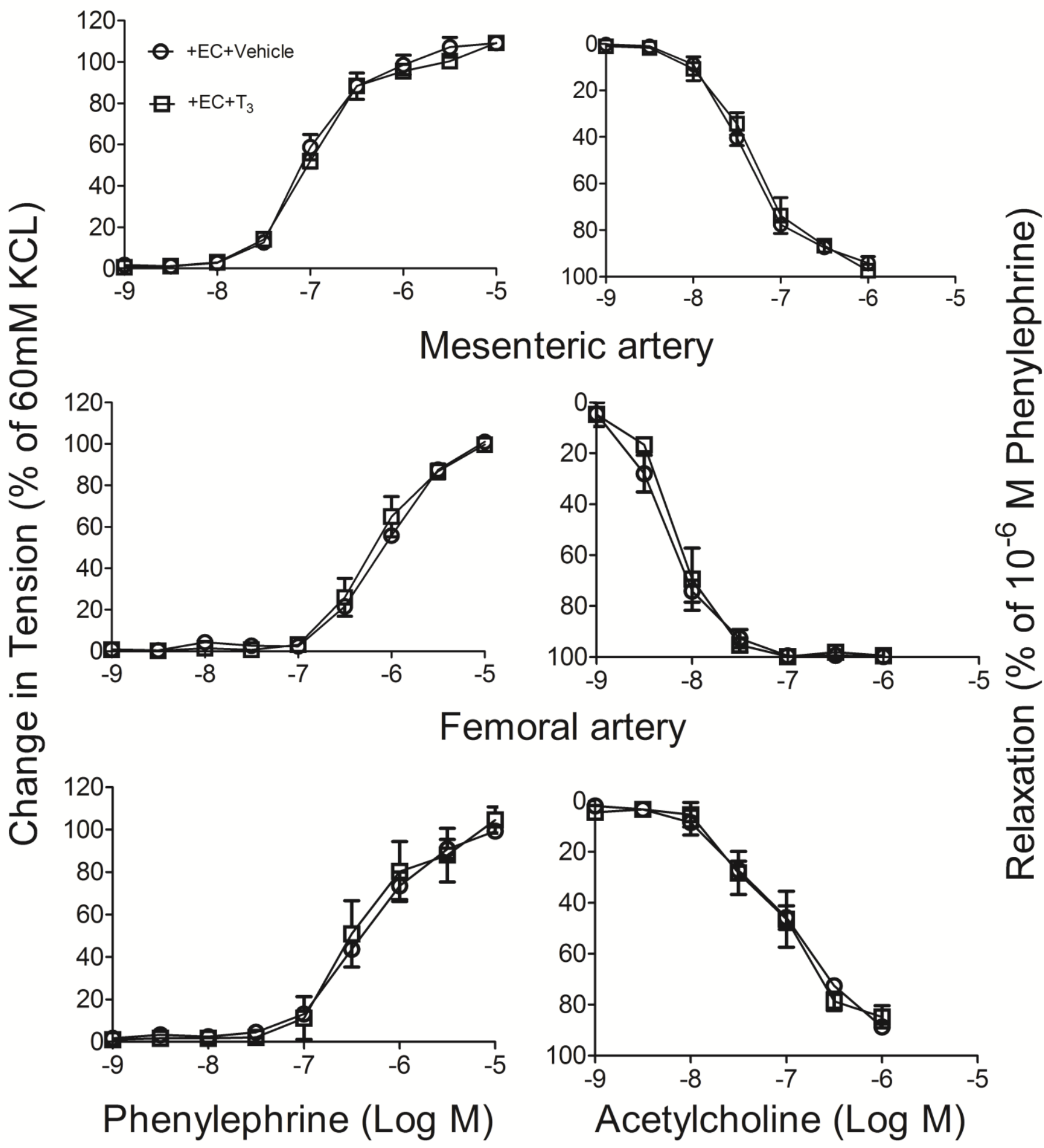


Fig. 3
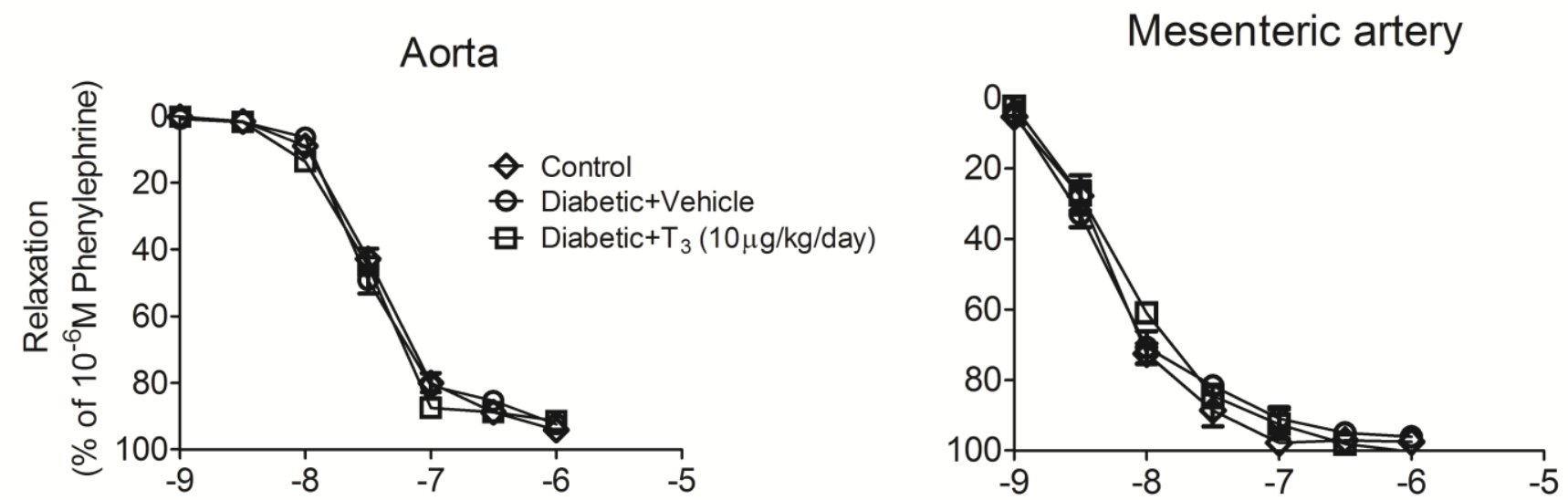

Acetylcholine (Log M) 
Fig. 4

Diabetic rat

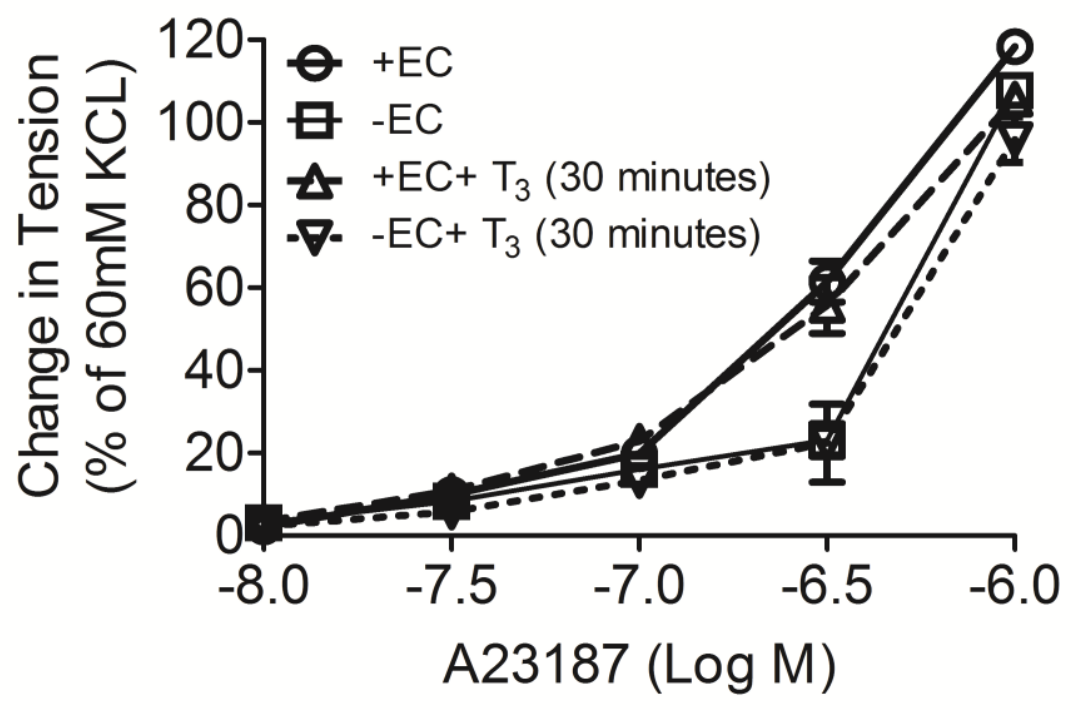


Fig. 5

Vehicle

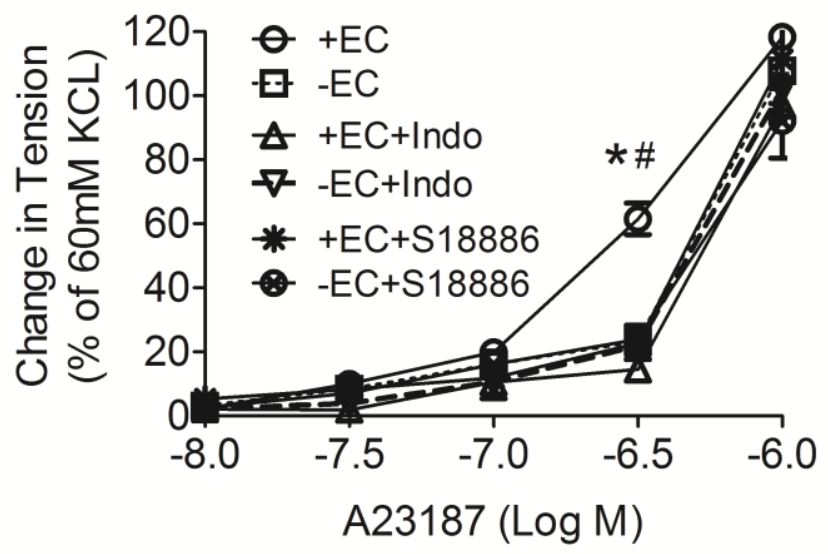

$\mathrm{T}_{3}(10 \mu \mathrm{g} / \mathrm{kg} / \mathrm{day})$

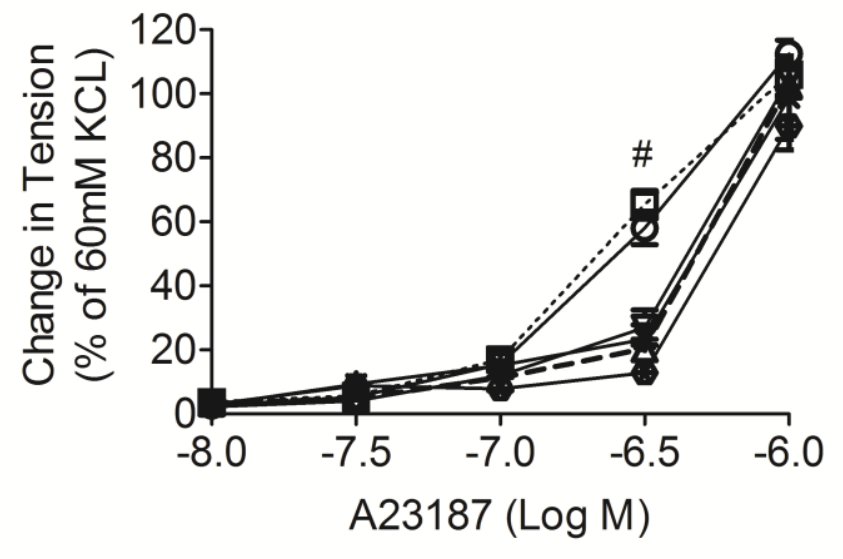


Fig. 6
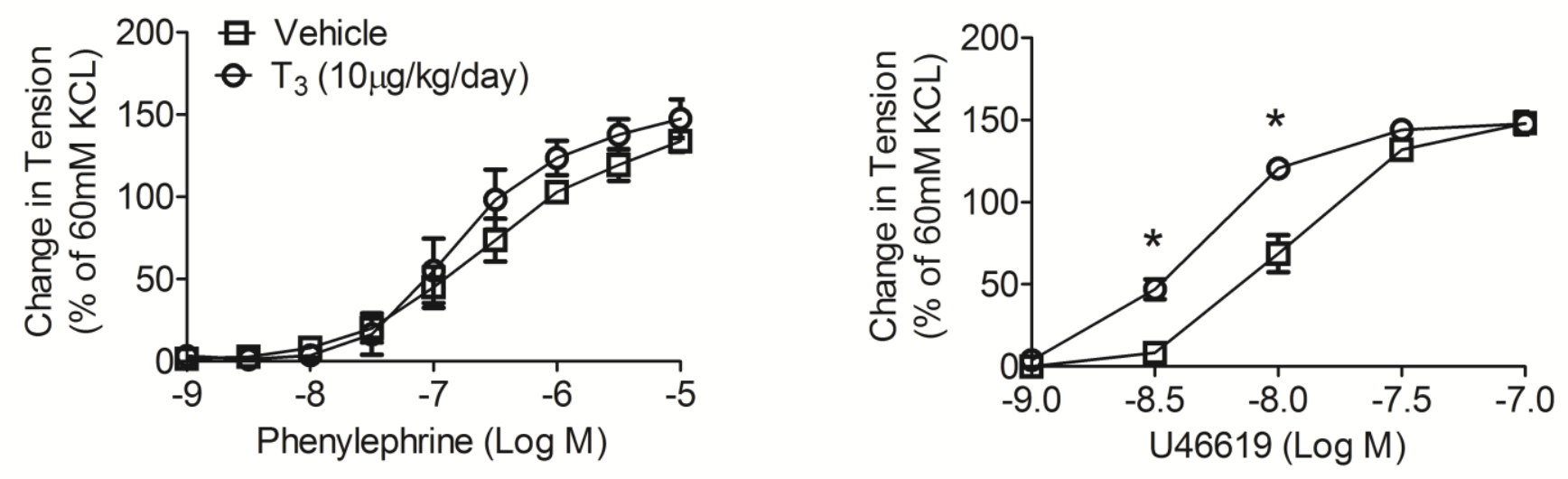
Fig. 7

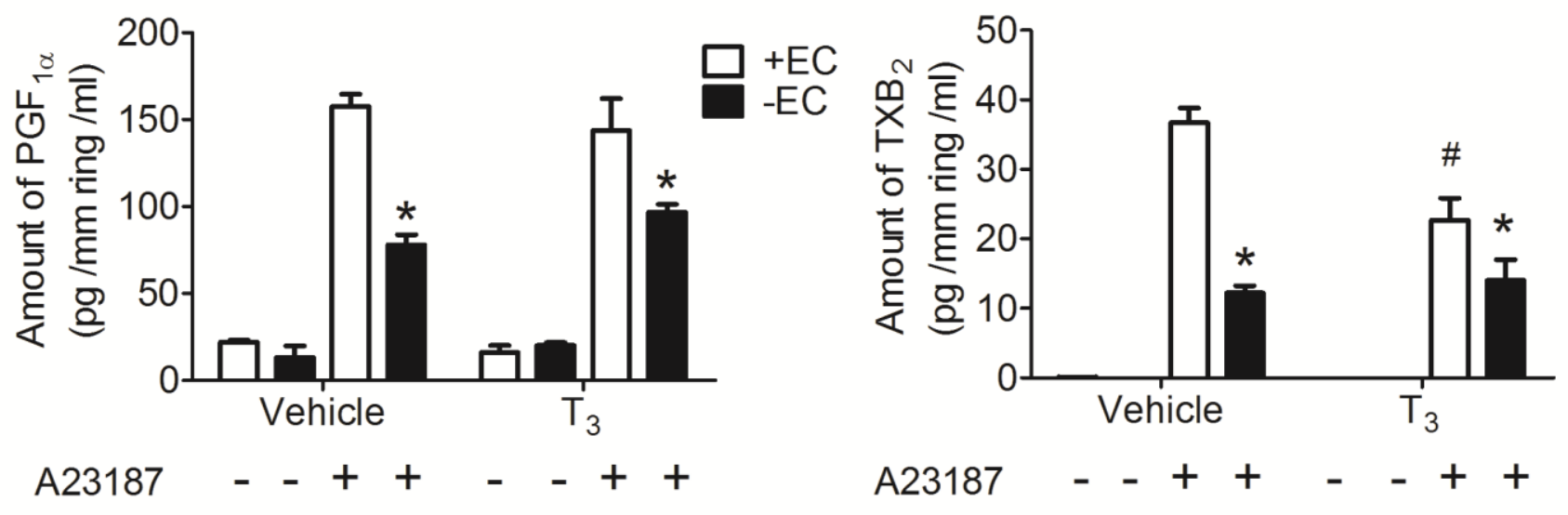


Fig. 8
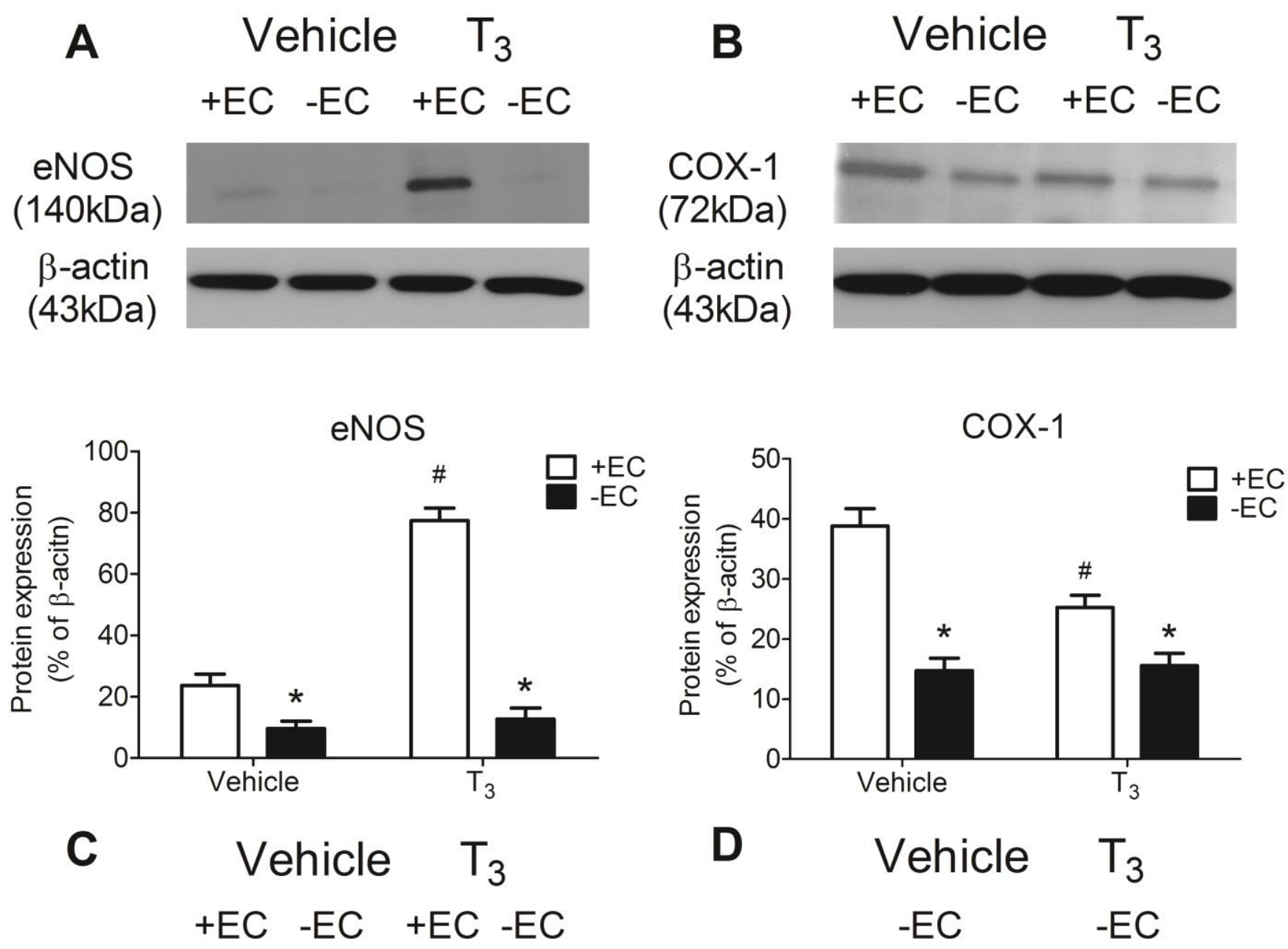

COX-2 (72kDa)

D

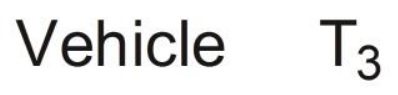
-EC -EC

TP receptor (55kDa)

$\beta$-actin (43kDa)

$\beta$-actin (43kDa)

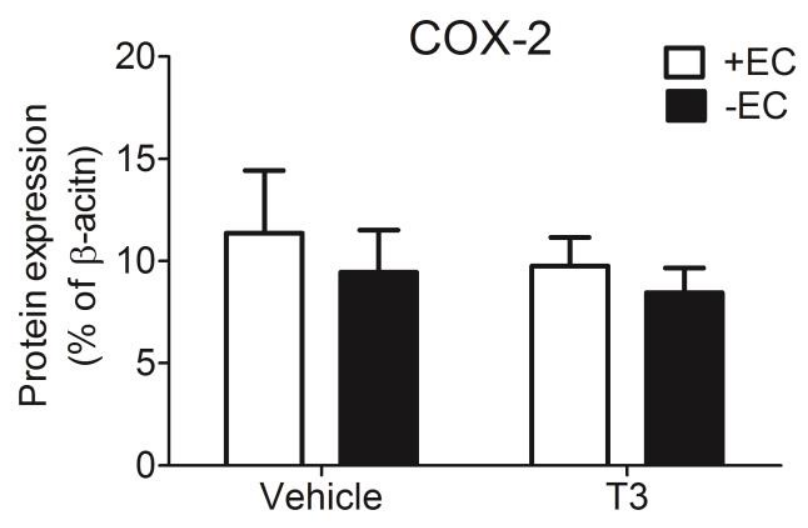

TP receptor

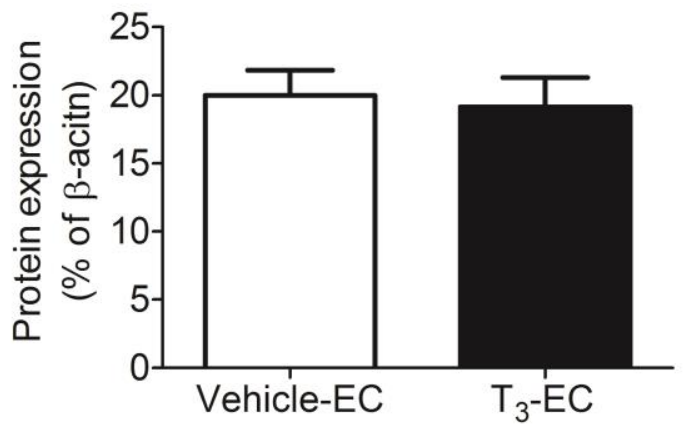


Fig. 9

$\begin{array}{lccccc}\mathrm{T}_{3}(\mathrm{M}) & 0 & 10^{-10} & 10^{-9} & 10^{-8} & 10^{-7} \\ \mathrm{IL}-1 \beta & + & + & + & + & +\end{array}$

eNOS

(140kDa)

COX-1

$(72 \mathrm{kDa})$

COX-2

$(72 \mathrm{kDa})$

$\beta$-actin

(43kDa)

eNOS $\left(T_{3}\right.$, one week, IL-1 $\beta$ )

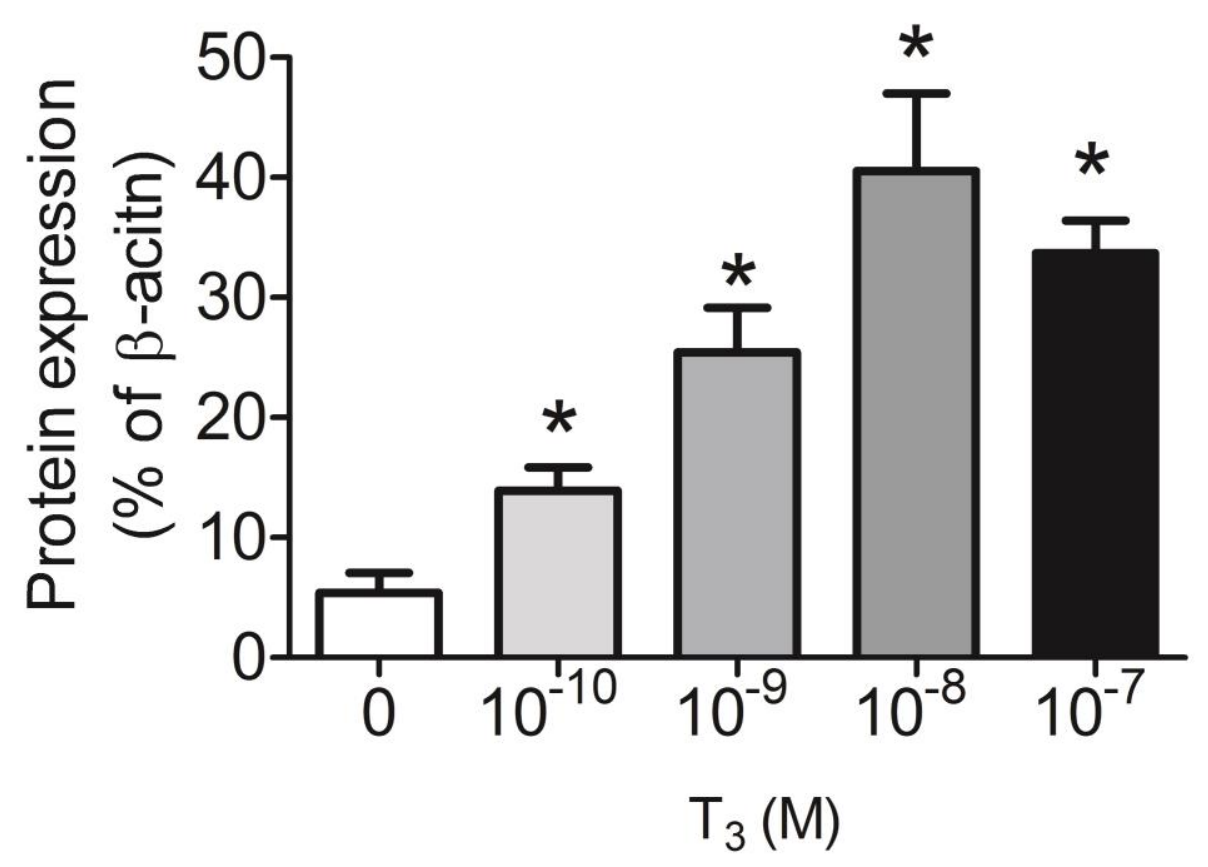


Fig. 10

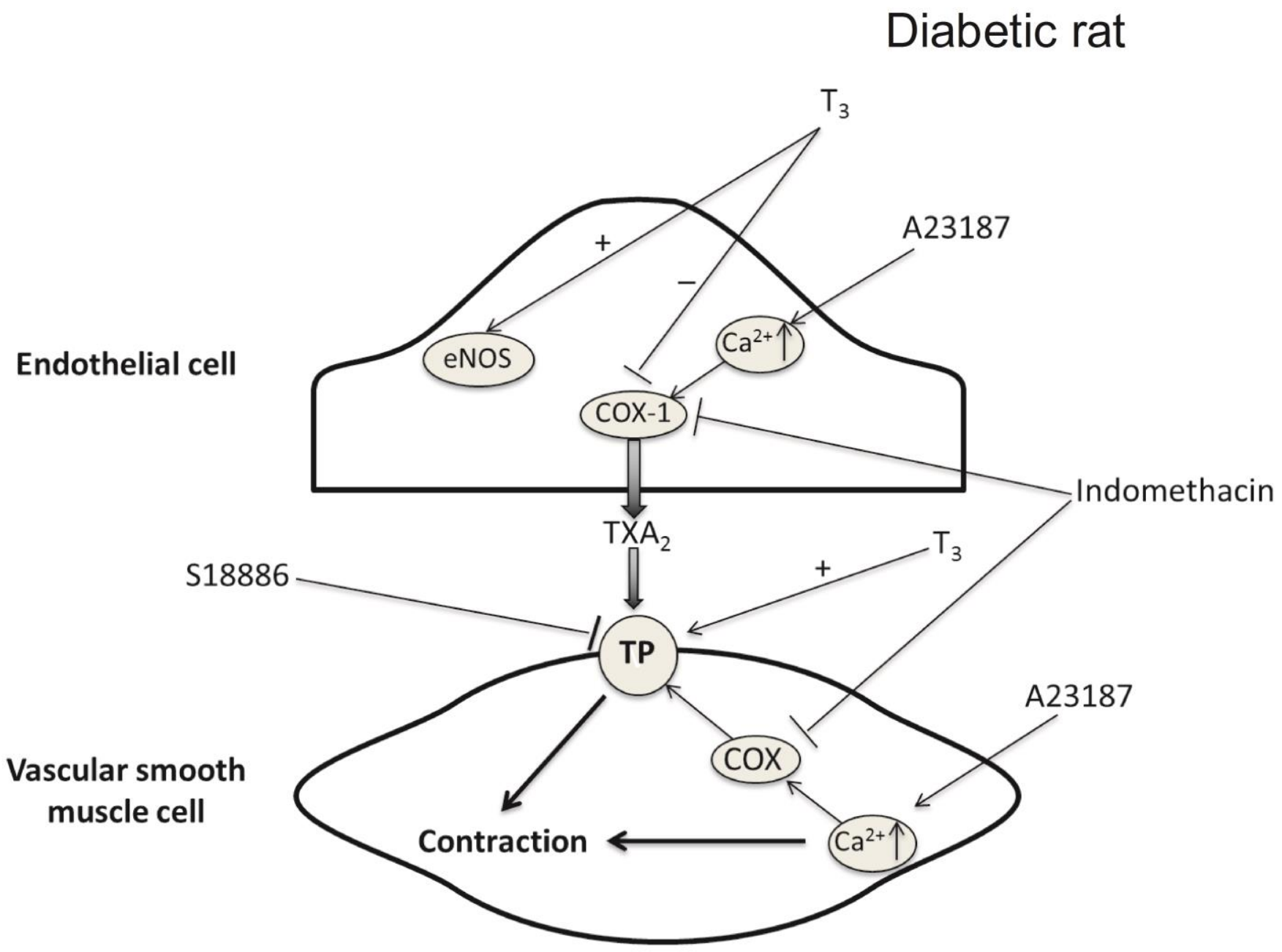


Table 1

Effects of various pharmacological inhibitors on the relaxation evoked by $T_{3}$ in rat mesenteric arteries ${ }^{\mathrm{a}}$.

\begin{tabular}{|c|c|c|c|c|}
\hline Treatment & $p E C_{50}$ of $T_{3} b$ & Concentration ${ }^{c}$ & Target $^{d}$ & Referencese \\
\hline Vehicle & $4.96 \pm 0.19$ & - & - & - \\
\hline Rp-8-Br-cAMPs & $4.89 \pm 0.22$ & $10^{-4} \mathrm{M}$ & protein kinase $\mathrm{A}$ & Keung et al., 2005 \\
\hline KT5823 & $4.86 \pm 0.11$ & $10^{-6} \mathrm{M}$ & protein kinase G & Keung et al., 2005 \\
\hline L-NAME & $4.93 \pm 0.13$ & $3 \times 10^{-4} \mathrm{M}$ & eNOS, iNOS & Shi et al., 2007a \\
\hline 1400W & $4.93 \pm 0.09$ & $10^{-5} \mathrm{M}$ & iNOS & Zhang et al., 2012 \\
\hline ODQ & $4.98 \pm 0.05$ & $10^{-5} \mathrm{M}$ & sGC & Li et al., 2013 \\
\hline Charybdotoxin & $5.14 \pm 0.45$ & $10^{-7} \mathrm{M}$ & $\mathrm{IK}_{\mathrm{Ca}}, \mathrm{BK}_{\mathrm{Ca}}$ & Edwards et al., 1998 \\
\hline Iberiotoxin & $4.89 \pm 0.23$ & $10^{-7} \mathrm{M}$ & $\mathrm{BK}_{\mathrm{Ca}}$ & Li et al., 2013 \\
\hline $\mathrm{BaCl}_{2}$ & $4.95 \pm 0.12$ & $10^{-6} \mathrm{M}$ & $\mathrm{K}_{\mathrm{IR}}$ & Li et al., 2013 \\
\hline Glibenclamide & $4.95 \pm 0.20$ & $10^{-5} \mathrm{M}$ & $K_{\text {ATP }}$ & Li et al., 2013 \\
\hline ouabain & $5.05 \pm 0.08$ & $5 \times 10^{-7} \mathrm{M}$ & $\mathrm{Na}^{+}-\mathrm{K}^{+}$-ATPase & Li et al., 2013 \\
\hline nifedipine & $4.85 \pm 0.13$ & $10^{-7} \mathrm{M}$ & L-type $\mathrm{Ca}^{2+}$-channel & Cognard et al., 1990 \\
\hline calhex 231 & $5.10 \pm 0.32$ & $3 \times 10^{-6} \mathrm{M}$ & CaSR & Weston et al., 2008 \\
\hline thapsigargin & $4.79 \pm 0.18$ & $10^{-6} \mathrm{M}$ & SERCA & Chan et al., 2011 \\
\hline pertussis toxin & $5.02 \pm 0.06$ & $400 \mathrm{ng} / \mathrm{ml}$ & $\mathrm{G}_{\alpha \mathrm{i}}$ proteins & Wong et al., 2010 \\
\hline$D-T r p-S P^{f}$ & $4.95 \pm 0.08$ & $10^{-5} \mathrm{M}$ & $\mathrm{G}_{\alpha q}$ proteins & Mukai et al., 1992 \\
\hline
\end{tabular}

a Preparations without endothelium were contracted with U46619 ( $\left.3 \times 10^{-8} \mathrm{M}\right)$.

b Values are means \pm S.E.M.; $n=6$ to 10

c Incubation during $30 \mathrm{~min}$, except for pertussis toxin (two h), prior to the contraction with U46619. 
${ }^{\mathrm{d}}$ Abbreviations: $\mathrm{BK}_{\mathrm{Ca}}$, large conductance $\mathrm{Ca}^{2+}$-activated potassium channel; CaSR, calcium sensing receptor; eNOS, endothelial nitric oxide synthase; $\mathrm{IK}_{\mathrm{Ca}}$, intermediate conductance $\mathrm{Ca}^{2+}$-activated potassium channel; iNOS, inducible nitric oxide synthase; $\mathrm{K}_{\mathrm{ATP}}$, ATP-sensitive $\mathrm{K}^{+}$channel; $\mathrm{K}_{\mathrm{IR}}$, inwardly-rectifying $\mathrm{K}^{+}$channel; SERCA, sarco/endoplasmic reticulum $\mathrm{Ca}^{2+}$-ATPases; $\mathrm{sGC}$, soluble guanylyl cyclase.

e Justifying the used concentration of the inhibitors.

${ }^{f}$ D-Trp-SP: [D-Trp $\left.{ }^{7,9,10}\right]-$ Substance P. 
Table 2

Body weight, blood glucose and serum $\mathrm{T}_{3}$ level in vehicle and $\mathrm{T}_{3}$ treated diabetic rats ${ }^{\mathrm{a}}$.

\begin{tabular}{|c|c|c|c|c|}
\hline & \multicolumn{2}{|c|}{ Vehicle } & \multicolumn{2}{|c|}{$\mathrm{T}_{3}$ treated $^{\mathrm{c}}$} \\
\hline & Before & $\mathrm{STZ} \mathrm{Z}^{\mathrm{b}}$ & Before & $\mathrm{STZ} \mathrm{Z}^{\mathrm{b}}$ \\
\hline Body weight (g) & $571.9 \pm 5.9$ & $423.4 \pm 9.0^{d}$ & $552.9 \pm 7.7$ & $414.9 \pm 10.5^{d}$ \\
\hline Blood glucose (mmol/L) & $5.8 \pm 0.2$ & $25.0 \pm 0.7^{e}$ & $5.7 \pm 0.2$ & $23.6 \pm 0.8^{e}$ \\
\hline Serum $T_{3}(n g / d L)$ & - & $226.8 \pm 20.1$ & - & $411.3 \pm 27.4^{f}$ \\
\hline
\end{tabular}

${ }^{\text {a }}$ Data shown as means \pm S.E.M.; $\mathrm{n}=10$ to 20 .

${ }^{\text {b } S t r e p t o z o t o c i n ~(S T Z ; ~} 30 \mathrm{mg} / \mathrm{kg}$; intraperitoneally; once per day for three consecutive days) was given followed by vehicle or $T_{3}$ treatment.

c Daily intraperitoneal injection of $\mathrm{T}_{3}(10 \mu \mathrm{g} / \mathrm{kg} / \mathrm{day})$ for four weeks.

${ }^{\mathrm{d}}$ Statistically significant difference in body weight between before and four weeks after streptozotocin treatment $(P<0.05)$

e Statistically significant difference in blood glucose level between before and four weeks after streptozotocin treatment $(P<0.05)$.

${ }^{f}$ Statistically significant difference in serum $T_{3}$ level between vehicle and $T_{3}$ treated diabetic rats $(P<0.05)$. 
Table 3

$\mathrm{pEC}_{50}$ to phenylephrine or U46619 in femoral arteries from vehicle and $\mathrm{T}_{3}$ treated diabetic rats ${ }^{\mathrm{a}}$.

\begin{tabular}{|c|c|c|c|c|}
\hline & \multicolumn{2}{|c|}{ Phenylephrine } & \multicolumn{2}{|c|}{ U46619 } \\
\hline & Vehicle $^{b}$ & $\mathrm{~T}_{3}$ treated $^{\mathrm{b}}$ & Vehicle $^{b}$ & $\mathrm{~T}_{3}$ treated $^{\mathrm{b}}$ \\
\hline $\mathrm{pEC}_{50}$ & $6.55 \pm 0.30$ & $6.76 \pm 0.21$ & $7.94 \pm 0.09$ & $8.53 \pm 0.06^{c}$ \\
\hline
\end{tabular}

a Data shown as means \pm S.E.M.; $n=5$ to 10 .

${ }^{\mathrm{b}}$ Vehicle or $\mathrm{T}_{3}$ treatment $(10 \mu \mathrm{g} / \mathrm{kg} /$ day; intraperitoneally) was given on diabetic rats for four weeks.

c Statistically significant difference in $\mathrm{pEC} 50$ to $\mathrm{U} 46619$ between vehicle and $\mathrm{T}_{3}$ treated diabetic rats $(\mathrm{P}<0.05)$. 